\title{
Influence of Subseasonal Variability on the Diurnal Cycle of Precipitation on a Mountainous Island: The Case of New Caledonia
}

\author{
DAMIEN SPECQ ${ }^{\mathrm{a}}$ \\ CNRM, Université de Toulouse, Météo-France, CNRS, Toulouse, France \\ GILlES BELLON \\ Department of Physics, University of Auckland, Auckland, New Zealand \\ AleXANDRE Peltier \\ Météo-France Nouvelle-Calédonie, Nouméa, New Caledonia \\ JÉRÔME LEFÈVRE \\ LEGOS/MIO, Institut de Recherche pour le Développement, Nouméa, New Caledonia \\ CHRISTOPHE MENKES \\ ENTROPIE, Institut de Recherche pour le Développement, Nouméa, New Caledonia
}

(Manuscript received 6 June 2019, in final form 24 September 2019)

\begin{abstract}
The relationship between the large-scale intraseasonal variability, synoptic wind regimes, and the local daily variability of precipitation over the main island of New Caledonia (southwest tropical Pacific) is investigated with a focus on the austral summer wet season (November-April). The average diurnal cycle of precipitation over the island is characterized by a sharp afternoon maximum around 1600 local time, with significant differences between the windward east coast, the leeward west coast, and the mountain range. The afternoon peak is related to the afternoon sea-breeze circulation and to the diurnal cycle of convection over land. In general, its magnitude follows the same evolution as the daily mean. In agreement with past studies, a clear modulation of the Madden-Julian oscillation (MJO) on both the diurnal cycle of precipitation and the probability of occurrence of four robust wind regimes can be identified in the New Caledonia region during the wet season. From the evidence that there is a qualitative correspondence between the effects of both the MJO phases and the wind regimes on features in the diurnal cycle of precipitation, a simple model is proposed to inspect the MJO forcing mediated by wind regimes on the diurnal variability of rain. The complete decomposition of the MJO impact shows that the modulation of diurnal cycle by the MJO relies on complex interactions between the MJO and synoptic winds that involve both large-scale MJO convective anomalies and MJO-induced modification of wind patterns.
\end{abstract}

\section{Introduction}

New Caledonia is a group of islands composing one of the largest and most populated territories in the tropical South Pacific. Located between $18^{\circ}-23^{\circ} \mathrm{S}$ and $163^{\circ}-169^{\circ} \mathrm{E}$,

\footnotetext{
${ }^{a}$ Additional affiliation: Direction de la Recherche, École des Ponts, Paris, France.

Corresponding author: Damien Specq, damien.specq@meteo.fr
}

about $1500 \mathrm{~km}$ east of Australia, it is made up of a long and narrow main island (the "Grande Terre" or Mainland) and other smaller islands. The main island is roughly $400 \mathrm{~km}$ long, $50 \mathrm{~km}$ wide, and features a central mountain range averaging $800 \mathrm{~m}$ in altitude, with the two highest peaks reaching around $1600 \mathrm{~m}$. On a climatological average, New Caledonia is swept by the South Pacific southeasterly trade winds that are almost parallel to the $45^{\circ}$ orientation of the Grande Terre (Lefèvre et al. 2010), as shown in Fig. 1. Although winter 


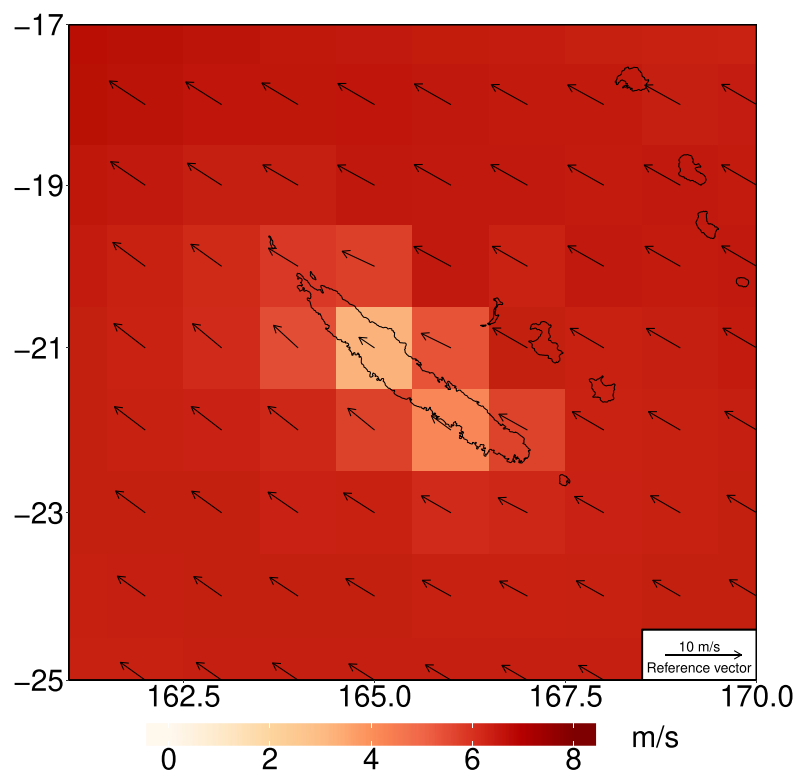

FIG. 1. Long-term mean 10-m wind velocity (vectors) and intensity (shadings) around New Caledonia.

temperatures frequently drop below $10^{\circ} \mathrm{C}$, it experiences a tropical climate with an average temperature of $18^{\circ} \mathrm{C}$ or higher every month of the year. The annual cycle of rainfall can be decomposed into a warm, wet season from November to April, peaking in the austral summer, and a dry, cold season from May to October. Rainfall is a paramount matter in New Caledonia. At the end of the dry season, agricultural activities and drinking water resources are particularly vulnerable to drought hazards on the West Coast plains. Subsequent rainy spells often come as a relief in the fight against wildfires considered as the main cause of degradation of primary forests and their unique ecosystem (Barbero et al. 2011). Reducing New Caledonia's vulnerability to heavy precipitating events is also a major concern as some inhabited areas are exposed to landslides and flash flooding (Governement de la Nouvelle-Calédonie 2016).

Heavy rainfall generally occurs on short time scales ranging from a few hours to a few days. Within these time scales, the diurnal cycle is expected to play an important role as it influences the timing of rainfall initiation or intensification. In the tropics, the diurnal cycle of convection and corresponding wind patterns control the timing of diurnal precipitation peaks (Mori et al. 2004). Over the open ocean, a precipitation maximum is generally reported at night or in the early morning (Yang and Smith 2006; Kikuchi and Wang 2008), resulting from convective instability created by nocturnal longwave radiative cooling in the mid- and upper troposphere. Over islands, studies in the Maritime Continent and the western Pacific have shown that provided the land surface is large enough, tropical islands are rainier than the open ocean and exhibit a diurnal cycle with a precipitation peak in the afternoon due to local forcings (Saito et al. 2001; Yang and Smith 2006; Kikuchi and Wang 2008; Vincent and Lane 2016). The main forcing is the sea breeze (Kikuchi and Wang 2008; Cronin et al. 2015). Owing to the smaller heat capacity of land surfaces compared to the ocean, the magnitude of the warming and cooling of the island with the day-night cycle is much larger than that of the ocean. A sea breeze develops in the afternoon when the land is warmer than the ocean and reverses into a land breeze at night when the land cools. Using an idealized model experiment of a flat, circular, low heat-capacity island, Cronin et al. (2015) have proposed a mechanism involving this land/sea-breeze cycle to explain the specific features of rainfall on tropical islands. The convergence at the seabreeze front is responsible for the formation of low-level convective clouds around noon, before these shallow clouds develop into deeper precipitating convective cells in the afternoon that eventually merge together and converge at the center of the island, triggering heavy rainfall in the late afternoon or early evening. Evidence of this process over real islands in the Maritime Continent is also shown in Qian (2008). Owing to the heavy afternoon rainfall, the island experiences heavier rainfall than the surrounding ocean. However, the size of the island and its orography also influence the rainfall pattern: according to Sobel et al. (2011), the larger the island, the more rainfall and for large islands, mountains increase precipitation. Indeed, in the case of mountainous islands, orographic effects can lead to further enhancement of the afternoon peak in the diurnal cycle. First, a mountain range tends to regularly experience afternoon cumulus formation because of the elevated surface heating, and is therefore a favorable place of its own for a strong diurnal cycle. Second, its interaction with the sea breeze is likely to intensify cumulus formation in the afternoon through orographic lifting (Yang and Chen 2008; Vincent and Lane 2016). As for New Caledonia, Lefèvre et al. (2010) showed that the main island exhibits a strong diurnal cycle in the wind that is related to a diurnal cycle in surface heating. They also highlighted an asymmetric sea-breeze pattern between the windward and leeward sides. Consequently, precipitation on the island is also expected to exhibit an asymmetric pattern in average rainfall, that has already been documented (Météo-France 2008), and a diurnal cycle that will be the purpose of this study.

At longer time scales, the climate in New Caledonia is influenced by large-scale meteorological patterns located both in the tropics and the midlatitudes of the 
Southern Hemisphere. Midlatitude highs and lows, and especially the Kermadec high, control the orientation of the prevailing trade winds, while tropical influences impact New Caledonia through the seasonal variations in the location of the South Pacific convergence zone (SPCZ, Griffiths et al. 2003). Being located to the south of the mean position of the SPCZ, New Caledonia's weather is impacted by the frequent southward shifts of the SPCZ in the wet season, which bring increased precipitation (Lefort 2005; Moron et al. 2016). Global modes of variability then modulate these climatological processes. At the interannual time scale, El NiñoSouthern Oscillation (ENSO) influences the orientation of the SPCZ (Vincent et al. 2011; Salinger et al. 2014) and the probability of occurrence of tropical cyclones, that is increased in La Niña phase and decreased in El Niño phase (Leroy and Wheeler 2008). At the subseasonal time scale, the Madden-Julian oscillation (MJO; Madden and Julian 1971) impacts wind patterns (Lefort 2005; Lefèvre et al. 2010), while it is also responsible for shifts in the SPCZ (Matthews 2012; Moron et al. 2016) and changes in the probability of observing a tropical cyclone (Leroy and Wheeler 2008). As a result, Leroy (2006) highlights an impact of the MJO on New Caledonia rainfall, and Moron et al. (2016) also show a modulation of rainfall by the subseasonal variability, although they need to use a tailor-made OLR-based intraseasonal index centered on New Caledonia to demonstrate it.

Moreover, the MJO not only impacts the daily rainfall but also the diurnal cycle around islands, as documented by several studies based on observations (Chen and Houze 1997; Sui et al. 1997; Tian et al. 2006; Suzuki 2009; Hidayat and Kizu 2009; Rauniyar and Walsh 2011; Oh et al. 2012; Kanamori et al. 2013; Peatman et al. 2014) and model simulations (Birch et al. 2016; Vincent and Lane 2017). These studies analyze the direct relationship between the MJO phase and the diurnal cycle of precipitation or convection with composite or case study analysis. Most of them focus on the Maritime Continent area. Their conclusions vary depending on mesoscale phenomena such as orographic effects and sea breeze, specific to the location under study. But they all highlight the differentiated impacts of MJO variability on the diurnal cycle between land and ocean. In particular, through the analysis of TRMM data, Peatman et al. (2014) come to the conclusion that, in the Maritime Continent, $80 \%$ of the modulation of the precipitation by the MJO over land result from MJO-induced changes of the amplitude of the diurnal cycle.

Finally, synoptic variability also influences daily rainfall and diurnal cycle over islands. Wind regimes enable to classify the synoptic atmospheric circulation around the area of interest into a few specific and recurrent patterns. They can be related to the large-scale, intraseasonal MJO variability by considering how the MJO modulates their probability of occurrence. They can also be related to the island mesoscale effects that are responsible for variations in the diurnal cycle. Wind regimes were used to study the diurnal cycle, for instance by Qian et al. (2013) over Borneo, by Moron et al. (2015) over the whole Maritime Continent, and more recently by Hopuare et al. (2019) over the Pacific island of Tahiti. In New Caledonia, Lefort (2005) and Leroy (2006) have shown that atmospheric conditions could be classified into a small number of regimes. Lefèvre et al. (2010) have also highlighted the link between wind regimes and the phases of the MJO. With a six-state classification performed on daily New Caledonia rainfall, Moron et al. (2016) have even managed to explain the relationships between the local precipitation and the large-scale atmospheric dynamics at various time scales. However, the link between the subseasonal variability and the diurnal cycle of precipitation in New Caledonia has not been investigated so far and the present study intends to fill this gap.

The following sections document the influence of the MJO and wind regimes on the diurnal cycle of rainfall over the main island of New Caledonia during the wet season, and investigate the relationship between wind regimes and MJO. Section 2 introduces the data and methodology used in this article. Section 3 is devoted to the change in diurnal cycle with synoptic and large-scale circulation. It first presents the influence of the MJO on rainfall and its diurnal cycle in New Caledonia, and that of wind regimes on the spatial variations of the diurnal cycle over the island, independently from the MJO's influence. Section 4 investigates the link between the MJO and the wind regimes and its impacts on the diurnal cycle. Finally, the main conclusions of the study are presented in section 5 .

\section{Data and methodology}

\section{a. Data}

As this study is carried out for the wet season, only the months from November to April will be considered in all datasets.

\section{1) LARGE-SCALE DATA}

Since the diurnal cycle of precipitation involves interactions between the large-scale atmospheric dynamics and the island's specific topography, surface wind is presumably the best field to determine wind regimes and investigate the dynamical signal of the MJO as seen 


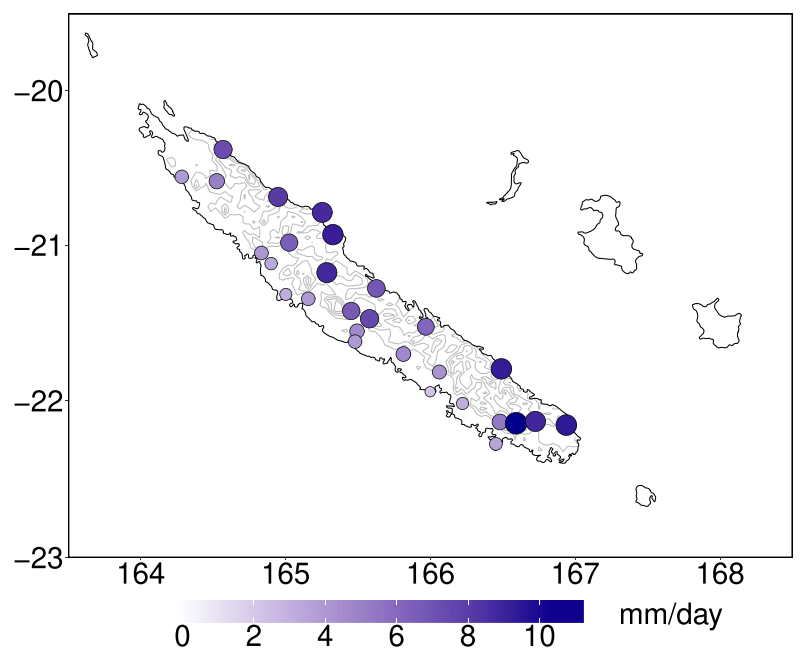

FIG. 2. Average precipitation at the 28 stations in wet season (NDJFMA). Gray lines indicate elevation levels every $200 \mathrm{~m}$ from 200 to 1000 m, retrieved from Shuttle Radar Topography Mission (SRTM) data.

by the island. For this purpose, the daily averaged $10-\mathrm{m}$ winds from the ERA-Interim reanalysis (Dee et al. 2011) are used at $1^{\circ}$ resolution over a small domain encompassing New Caledonia $\left(25^{\circ}-17^{\circ} \mathrm{S}, 161^{\circ}-170^{\circ} \mathrm{E}\right)$. The period considered is 1 January 1979-31 December 2017 (39 years). ERA-Interim 10-m winds are also considered at a lower resolution of $2^{\circ}$ on a large tropical domain $\left(30^{\circ} \mathrm{S}-0^{\circ}, 50^{\circ}-240^{\circ} \mathrm{E}\right)$ in order to represent the circulation anomalies associated to the MJO, along with OLR anomalies computed from the daily averaged OLR from NOAA's polar-orbiting satellites (Liebmann and Smith 1996).

\section{2) New Caledonia Rainfall data}

A comprehensive study of the diurnal cycle of precipitation requires the use of high-frequency rainfall data, ideally with an hourly or shorter time step. This work relies on the Météo-France hourly rain gauge data for 28 stations scattered all over the main island of New Caledonia. These stations were chosen among the available stations according to three criteria: they provided hourly rain rates, they had a sufficiently long record over the year and they were deemed reliable by the Météo-France climatological services in New Caledonia. These stations are listed in Table A1 and shown on the map in Fig. 2. We deliberately choose to focus this study on the main island owing to the smaller sizes and the very different topographic profiles of the other islands, which make them likely to exhibit a diurnal cycle that would be governed by different mechanisms. The period of available data is station-dependent and some stations present periods of missing values. To include as much data as possible, the period considered is 1 January 1991-31 December 2017 (27 years), 1991 being the year when the first hourly records started.

\section{3) MJO INDEX}

Wheeler and Hendon (2004) have defined a set of two indices to represent the propagation of the MJO and classify every day with significant MJO activity into one of the eight phases representing the location of the convective envelope. These two Real-time Multivariate MJO indices (RMM1 and RMM2) are computed operationally at the Australian Bureau of Meteorology (BoM) from NOAA OLR data (as a proxy for cloud amount) and NCEP2 reanalysis zonal winds at lower $(850 \mathrm{hPa})$ and upper $(200 \mathrm{hPa})$ levels of the atmosphere. In this study, the indices' values were retrieved directly from the BoM website for the period from 1 January 1979 to 31 December 2017. The (RMM1, RMM2) phase space is separated into eight quadrants and the location of a point indicates the MJO phase. In this phase space, a "canonical" MJO event will be represented with a counterclockwise trajectory, the phase for each day going from 1 to 8 . Note that when the amplitude of the MJO [i.e., the norm of the (RMM1, RMM2) vector], is less than 1, the MJO is considered to be weak (no MJO event) and the classification of the days into phases is no longer relevant.

\section{b. Wind regime classification}

Wind regime classification aims at sorting out the regional wind maps around New Caledonia (i.e., in the selected $25^{\circ}-17^{\circ} \mathrm{S}, 161^{\circ}-170^{\circ} \mathrm{E}$ domain) into a few specific and distinct circulation patterns. For this purpose, we use the same method as Lefèvre et al. (2010), Moron et al. (2015) and Hopuare et al. (2019), which is based on a $k$-means clustering algorithm. Zonal and meridional components of the daily mean $10-\mathrm{m}$ wind data at the 90 grid points in the domain were used for each day of the wet season. Standardized anomalies were computed at each grid point by subtracting the long-term mean and dividing by the corresponding standard deviation. Principal component analysis was performed to filter out the smallest scales of spatial variability and the first two principal components, accounting for $69 \%$ of the total variance, were retained. The 7069 days of the 39 wet seasons were partitioned in this two-dimensional space using the $k$-means clustering algorithm with Euclidean distance. The optimal number of clusters was chosen using a classifiability index as described by Michelangeli et al. (1995). The $k$-means clustering algorithm takes the user-provided $k$ number of clusters to choose $k$ initial 
centroids (the seeds) at random among the points to classify. The clusters are created by gathering each point to its closest cluster, and a new centroid is computed for each cluster. This step is repeated until the algorithm converges (i.e., no more changes in the clusters with the next iteration). The classifiability index is computed for each number of clusters $k$. For a given $k, N$ different partitions are computed. The similarity between two partitions is taken as the largest of the $k$ correlations (in the initial wind field space) between the pairs of corresponding centroids. The classifiability index is the average of the similarities in $N(N-1) / 2$ possible pairs of partitions. In this study, the classifiability index was calculated for a number of clusters $k$ from 2 to 10 and $N=50$. The closer the classifiability index is to 1 , the less the partition depends on the random initial seeds and the more robust it is.

\section{c. Quantifying the difference between two diurnal cycles}

A diurnal cycle of precipitation is an array of 24 values, one for each hour of the day. To quantify the difference between two diurnal cycles, we define a distance between the diurnal cycles $\mathbf{r}_{1}$ and $\mathbf{r}_{2}$ as the Euclidean norm of $\mathbf{r}_{1}-\mathbf{r}_{2}$ :

$$
\left\|\mathbf{r}_{1}-\mathbf{r}_{2}\right\|=\sqrt{\left\langle\mathbf{r}_{1}-\mathbf{r}_{2} \mid \mathbf{r}_{1}-\mathbf{r}_{2}\right\rangle}=\sqrt{\sum_{t=1}^{24}\left[\mathbf{r}_{1}(t)-\mathbf{r}_{2}(t)\right]^{2}},
$$

which is constructed from the scalar product. The smaller the distance, the more similar $\mathbf{r}_{1}$ and $\mathbf{r}_{2}$. For more convenience, the squared distance $\left\|\mathbf{r}_{1}-\mathbf{r}_{2}\right\|^{2}$, rather than the distance itself, will be used as a metric in the following sections to compare the diurnal cycle within the MJO phases and the wind regimes to the long-term mean diurnal cycle. The significance of the distance between the average diurnal cycle of a given MJO phase (respectively wind regime) to the long-term mean diurnal cycle is assessed through bootstrapping. If $n$ is the number of days in the MJO phase (respectively wind regime) and $N_{t}$ the total number of days, 10000 average diurnal cycles for random subsets of $n$ days among the total $N_{t}$ are constructed and the corresponding 10000 distances to the long-term mean diurnal cycle are computed. The distance in the MJO phase (respectively wind regime) is significant if it is higher than the 95th percentile of the distribution of distances determined from the 10000 random draws.

Moreover, the diurnal cycles $\mathbf{r}_{1}$ and $\mathbf{r}_{2}$ can also be decomposed into the sum of their daily mean and the diurnal cycle of the anomalies relative to this daily mean. For instance,

$$
\mathbf{r}_{1}=r_{1}^{m}+\mathbf{r}_{1}^{\mathbf{d}},
$$

where $r_{1}^{m}$ is the daily mean and $\mathbf{r}_{1}^{\mathbf{d}}$ the anomalies of the diurnal cycle relative to $r_{1}^{m}$. The squared distance $\left\|\mathbf{r}_{1}-\mathbf{r}_{2}\right\|^{2}$ can therefore be written as

$$
\left\|\mathbf{r}_{1}-\mathbf{r}_{2}\right\|^{2}=24\left(r_{1}^{m}-r_{2}^{m}\right)^{2}+\left\|\mathbf{r}_{1}^{\mathbf{d}}-\mathbf{r}_{2}^{\mathbf{d}}\right\|^{2} .
$$

The first term on the right-hand side of Eq. (3) represents the contribution of the difference in daily means, and the second term is the contribution of the difference in diurnal variability.

\section{d. Spatial classification of rain gauge stations}

A classification of the 28 rain gauge stations was performed in order to distinguish several geographical zones which exhibit significantly different diurnal cycles of rainfall. Similar to any clustering problem, such a classification requires the definition of an accurate metric of the difference between the items being classified (i.e., rain gauge stations). Our main purpose in this study is to illustrate, for each geographical zone, the influence of the wind regime on the diurnal cycle. For each station, we computed the smoothed composite diurnal cycle for each wind regime by averaging hourly rainfall over the days belonging to that regime and filtering out all harmonics with periods below $8 \mathrm{~h}$. Given that four wind regimes (see section 3 ) were finally retained, each station is characterized by 96 parameters corresponding to the 24 hourly rain rate values of its smoothed composite diurnal cycle in each of the four regimes. The metric used to quantify the difference between two stations was the square-rooted sum of the squared differences in this 96-parameter space. This metric is relevant for this case as it takes into account both the average rainfall at the station and the diurnal variation: if two stations receive similar rainfall on average, they will be close to each other but they will be even closer if, for instance, they also have similar diurnal peak. The clustering algorithm used for this classification is hierarchical clustering. At each step, the two closest clusters according to Ward's minimum variance method were merged together. The optimal number of clusters could be determined thanks to the dendrogram to ensure that the clusters were well separated from each other.

\section{e. Statistical testing of the influence of $M J O$ on the frequency of wind regimes}

To assess the statistical link between the MJO and the wind regimes, a contingency table showing the classification of wet-season days both into MJO phases and into wind regimes was built. The contingency table was 
submitted to a chi-square test (Wilks 2006) for each column representing a given wind regime. The null hypothesis states that the frequency of occurrence of the regimes does not depend on the MJO phase, which gives an expected distribution of the wind regimes that is similar to the overall distribution. The observed distribution is compared to the expected distribution under the null hypothesis through the chi-square indicator:

$$
\chi^{2}=\sum_{\phi=1}^{N_{\phi}=9} \sum_{i=1}^{N_{w}} \frac{\left(O_{\phi i}-E_{\phi i}\right)^{2}}{E_{\phi i}} .
$$

MJO phases are indicated with the subscript $\phi$ and wind regimes are indicated with the subscript $i . O_{\phi i}$ is the observed number of days in wind regime $i$ and MJO phase $\phi$, while $E_{\phi i}$ is the corresponding number of days that would be expected if the proportion of days in regime $i$ among the days in MJO phase $\phi$ were the same as the overall proportion of days in regime $i$ among all days. $N_{w}$ is the number of wind regimes and $N_{\Phi}=9$ is the number of MJO phases (including weak MJO). Given the null hypothesis described above, the expected value $E_{\phi i}$ is given by

$$
E_{\phi i}=\frac{N_{\text {days }}(\phi) \times N_{\text {days }}(i)}{N_{t}} .
$$

where $N_{t}$ is the total number of wet season days in this study from 1979 to 2017 (i.e., $N_{t}=7069$ ), while $N_{\text {days }}(\phi)$ [respectively $N_{\text {days }}(i)$ ] is the number of days in MJO phase $\phi$ (respectively wind regime $i$ ).

The $\chi^{2}$ indicator was computed separately for each regime. Under the null hypothesis, it follows a chisquare distribution with $N_{\Phi}-1=8$ degrees of freedom. The $p$ value gives the probability that the observed distribution of the given regime within the MJO phase could be obtained at random. The null hypothesis is rejected at the $95 \%$ confidence level if the $p$ value is less than 0.05 . If the chi-square test allows to reject the null hypothesis, the contribution of each phase in this rejection can be assessed through the use of Pearson's residuals:

$$
R_{\phi i}=\frac{O_{\phi i}-E_{\phi i}}{\sqrt{E_{\phi i}}}
$$

Because they are generally assumed to follow a normal distribution with mean 0 and standard deviation 1 , the Pearson's residuals with values less than -2 or greater than +2 are considered to indicate the phases for which the deviation from the expected distribution of the wind regimes under the null hypothesis is significant. These phases are the largest contributors to the rejection of the chi-square null hypothesis. Given their regime-phase symmetry, Pearson's residuals similarly indicate if a regime is significantly more or less frequent within a phase. The over or underrepresentation at the $95 \%$ level of a given regime within a MJO phase was also tested with bootstrapping. This method leads to conclusions that are identical to the Pearson's residuals approach.

\section{f. Impact of the interaction between the MJO and wind regimes on the diurnal cycle of precipitation}

To understand how the interaction between the MJO and wind regimes impacts the diurnal cycle, a method is proposed based on two simple but opposite models.

In this section, all diurnal cycle anomalies relative to the average diurnal cycle will be noted with a prime $\left({ }^{\prime}\right)$ :

$$
\mathbf{r}_{\phi}^{\prime}=\mathbf{r}_{\phi}-\overline{\mathbf{r}}
$$

with $\mathbf{r}_{\phi}^{\prime}$ the diurnal cycle anomaly in MJO phase $\phi$ and $\overline{\mathbf{r}}$ the average diurnal cycle. MJO phases are indicated with the subscript $\phi$ and wind regimes are indicated with the subscript $i$.

By definition, the diurnal cycle anomaly in MJO phase $\phi$ is the mean of the diurnal cycle anomalies of each regime in MJO phase $\phi$, weighted by the frequencies of the regimes in the phase:

$$
\mathbf{r}_{\phi}^{\prime}=\sum_{i=1}^{N_{w}} f_{i \phi} \mathbf{r}_{\mathbf{i} \phi}^{\prime}
$$

Let us rewrite Eq. (8) as

$$
\mathbf{r}_{\phi}^{\prime}=\sum_{i=1}^{N_{w}}\left[f_{i}+\left(f_{i \phi}-f_{i}\right)\right]\left[\mathbf{r}_{\mathbf{i}}^{\prime}+\left(\mathbf{r}_{\mathbf{i} \phi}^{\prime}-\mathbf{r}_{\mathbf{i}}^{\prime}\right)\right]
$$

where we have introduced the perturbation of regime frequencies $\left(f_{i \phi}-f_{i}\right)$ in MJO phase $\phi$, and the deviations $\left(\mathbf{r}_{\mathbf{i} \phi}^{\prime}-\mathbf{r}_{\mathbf{i}}^{\prime}\right)$ of the regime diurnal cycle in that MJO phase from the mean regime diurnal cycle. The expansion of (9) yields:

$$
\mathbf{r}_{\phi}^{\prime}=\sum_{i=1}^{N_{w}} f_{i \phi} \mathbf{r}_{\mathbf{i}}^{\prime}+\sum_{i=1}^{N_{w}} f_{i} \mathbf{i}_{\mathbf{i} \phi}^{\prime}-\sum_{i=1}^{N_{w}} f_{i} \mathbf{r}_{\mathbf{i}}^{\prime}+\sum_{i=1}^{N_{w}}\left(f_{i \phi}-f_{i}\right)\left(\mathbf{r}_{\mathbf{i} \phi}^{\prime}-\mathbf{r}_{\mathbf{i}}^{\prime}\right) .
$$

By definition, $\sum_{i=1}^{N_{w}} f_{i}=1$ and $\sum_{i=1}^{N_{w}} f_{i} \mathbf{r}_{\mathbf{i}}=\overline{\mathbf{r}}$, which leads to $\sum_{i=1}^{N_{w}} f_{i} \mathbf{r}_{\mathbf{i}}^{\prime}=0$.

Therefore, an exact decomposition of the diurnal cycle anomaly $\mathbf{r}_{\phi}^{\prime}$ in MJO phase $\phi$ is: 


$$
\mathbf{r}_{\phi}^{\prime}=\sum_{i=1}^{N_{w}} f_{i \phi} \mathbf{r}_{\mathbf{i}}^{\prime}+\sum_{i=1}^{N_{w}} f_{i} \mathbf{r}_{\mathbf{i} \phi}^{\prime}+\sum_{i=1}^{N_{w}}\left(f_{i \phi}-f_{i}\right)\left(\mathbf{r}_{\mathbf{i} \phi}^{\prime}-\mathbf{r}_{\mathbf{i}}^{\prime}\right) .
$$

In Eq. (11), the third sum on the right-hand side is a nonlinear, second-order residual term. The first term on the right-hand side of this equation is the contribution of the modification of the frequencies of occurrence of wind regimes. A simple model (Model 1) would be to assume that this term is dominant, as in the qualitative analysis carried out in previous studies on other regions (Ichikawa and Yasunari 2008; Hopuare et al. 2019). In this simple model,

$$
\mathbf{r}_{\phi}^{\prime} \simeq \sum_{i=1}^{N_{w}} f_{i \phi} \mathbf{r}_{\mathbf{i}}^{\prime}
$$

which corresponds to assuming that the characteristics of the regimes (wind direction and intensity, and characteristic precipitation patterns on the islands) are the same in all phases of the MJO.

An opposite model (Model2) would be to assume that the first term on the right-hand side of Eq. (11) is negligible, and that the second term, which is the contribution of regime change, is dominant:

$$
\mathbf{r}_{\phi}^{\prime} \simeq \sum_{i=1}^{N_{w}} f_{i} \mathbf{r}_{\mathbf{i} \phi}^{\prime}=\sum_{i=1}^{N_{w}} f_{i}\left(\mathbf{r}_{\mathbf{i} \phi}-\mathbf{r}_{\mathbf{i}}\right) .
$$

This corresponds to considering that the characteristics of the regimes change between phases of the MJO, but the frequency of these regimes do not change. Equation (13) also shows that the deviations of the diurnal cycle $\mathbf{r}_{\mathbf{i} \phi}$ can be taken from the longterm mean $\overline{\mathbf{r}}$ or from the characteristic diurnal cycle of each regime $\mathbf{r}_{\mathbf{i}}$.

We can expect the observed diurnal cycles to follow a pattern somewhat in between the two extreme simple models 1 and 2, and we can actually determine which model is closest to the observations.

The squared distances to the long-term mean diurnal cycle can be expressed as

$$
\|\mathbf{r}\|^{2}=\left\langle\mathbf{r}_{\phi}^{\prime} \mid \mathbf{r}_{\phi}^{\prime}\right\rangle .
$$

According to Eq. (11), this can be decomposed as

$$
\begin{aligned}
\left\|\mathbf{r}_{\phi}^{\prime}\right\|^{2}= & \sum_{i=1}^{N_{w}} f_{i \phi}\left\langle\mathbf{r}_{\phi}^{\prime} \mid \mathbf{r}_{\mathbf{i}}^{\prime}\right\rangle+\sum_{i=1}^{N_{w}} f_{i}\left\langle\mathbf{r}_{\phi}^{\prime} \mid \mathbf{r}_{\mathbf{i} \phi}^{\prime}\right\rangle \\
& +\sum_{i=1}^{N_{w}}\left(f_{i \phi}-f_{i}\right)\left\langle\mathbf{r}_{\phi}^{\prime} \mid \mathbf{r}_{\mathbf{i} \phi}^{\prime}-\mathbf{r}_{\mathbf{i}}^{\prime}\right\rangle,
\end{aligned}
$$

and, according to Eq. (13), it can be rewritten as

$$
\left\|\mathbf{r}_{\phi}^{\prime}\right\|^{2}=\sum_{i=1}^{N_{w}} f_{i \phi}\left\langle\mathbf{r}_{\phi}^{\prime} \mid \mathbf{r}_{\mathbf{i}}^{\prime}\right\rangle+\sum_{i=1}^{N_{w}} f_{i}\left\langle\mathbf{r}_{\phi}^{\prime} \mid \mathbf{r}_{\mathbf{i} \phi}-\mathbf{r}_{\mathbf{i}}\right\rangle+\mathbf{s} .
$$

This decomposition into $2 \times N_{w}+1$ terms, which are scalar products of anomalous diurnal cycles against the anomalous diurnal cycle of the MJO phase, represents the contributions of all phenomena responsible for the change in the diurnal cycle within the MJO phase. The first term on the right-hand side of Eq. (16) represents the difference to the long-term mean diurnal cycle accounted for by the change in frequency of each of the $N_{w}$ regimes, following Model 1. The second term on the right-hand side of Eq. (16) terms represents the difference to the long-term mean diurnal cycle accounted for by the change in the diurnal cycle of the regime within the MJO phase relative to the average diurnal cycle of the regime, according to Model 2. Here $\mathbf{s}$ is the secondorder residual term.

\section{Influence of large-scale dynamics on the diurnal cycle of rainfall}

\section{a. Climatology of rainfall in New Caledonia}

The average daily rainfall received in the wet season by the 28 selected rain gauge stations is represented in Fig. 2. The rainiest stations are all along the east coast and at specific locations inland that correspond to mountain peaks or passes. Stations along the west coast are comparatively drier. This east-west contrast is usually explained by two factors. First, with the presence of the central mountain range and the east-southeasterly climatological direction of the trade winds (illustrated in Fig. 1), orographic lifting on the windward side combined with foehn effect on the lee side drive a wetter climate along the east coast and a drier climate along the west coast (Météo-France 2008). Second, rainfall in New Caledonia can also be triggered by the advection of warm and moist tropical air masses by northerly and easterly winds that therefore preferentially hit the east coast (Moron et al. 2016).

The diurnal cycle of observed rainfall is represented in Fig. 3 for both the warm, wet (November-April) and the cool, dry (May-October) seasons, averaged over all stations shown in Fig. 2. While there is a strong diurnal cycle in the warm season, with a marked afternoon peak at 1600 local time and a secondary peak at night, rainfall in the dry season shows very little diurnal variation. As detailed in section 1, sea breeze and orographic effects are likely to explain the afternoon maximum in warm convection, and therefore in precipitation, over land (Cronin et al. 2015). Nighttime convection over the open ocean and advection of 


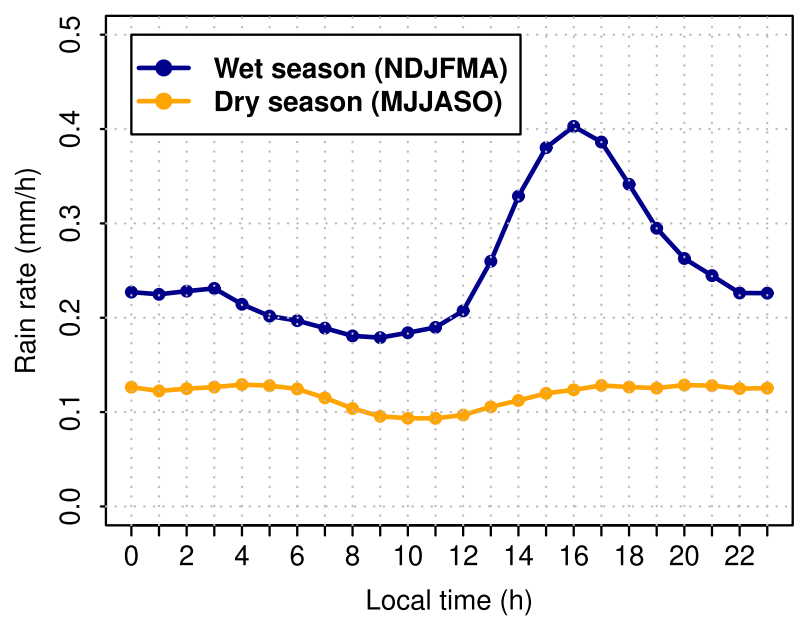

FIG. 3. Mean diurnal cycle of rainfall $\left(\mathrm{mm} \mathrm{h}^{-1}\right)$ averaged over the 28 stations in the wet season (blue) and the dry season (orange).

precipitating clouds by large-scale winds can presumably account for the secondary, nocturnal maximum. During the dry season, the sea surface temperature is lower and the troposphere is much drier than in the warm season: these inhibit deep convection, resulting in lower precipitation rates. The diurnal solar forcing is also smaller in that season, so it creates weaker land/sea surface temperature gradient and sea breeze, which is rarely strong enough to break through the convective inhibition. The diurnal cycle is therefore considered to be one major player to explain differences in rainfall rates between wet and dry season.

\section{b. Impact of the MJO on the diurnal cycle of rainfall in New Caledonia}

The influence of the MJO on the mean precipitation in New Caledonia (averaged over the 28 stations) is displayed in Fig. 4a, along with the $95 \%$ confidence interval determined from a bootstrap procedure (for each phase, 10000 draws of the days in the phase are performed with replacement). Daily mean rainfall variation oscillates with the MJO, following the propagation of the MJO convective envelope. Phases 4, 5, and 6 are the rainiest phases, and in particular, they are significantly rainier at the $95 \%$ confidence level than phases 1 and 2 which are the driest phases. This is in agreement with the MJOinduced OLR anomalies over New Caledonia as shown in Fig. 5: the largest negative OLR anomalies over New Caledonia, associated with intensified convection, are found in phases 4,5 , and 6 , while the largest positive OLR anomalies, associated with suppressed convection, correspond to phases 1 and 2. Figure 5 also shows that New Caledonia is located at the southern edge of the strong, equatorial MJO signal and it experiences convection anomalies in advance compared to the equatorial band. Positive or negative MJO-induced convection anomalies extend southeastward from the heart of the equatorial convective patch. For instance, New Caledonia experiences intensified convection when the equatorial convective envelope is located over the Maritime Continent (phase 5), while it experiences reduced convection when the equatorial convective envelope is roughly north of New Caledonia (phase 7).

The influence of the MJO on the diurnal cycle is summarized in Fig. 4b which shows the evolution of the diurnal amplitude with the MJO phase, along with its $95 \%$ bootstrap confidence interval. The diurnal amplitude is defined as the difference between the maximum and the minimum of the composite diurnal cycle of each MJO phase. The impact of the MJO on the diurnal amplitude is less clear than that on average precipitation considering the error bars are larger, but it also exhibits noteworthy features. The diurnal amplitude is largest for phase $4-6$, which means that the diurnal cycle tends to

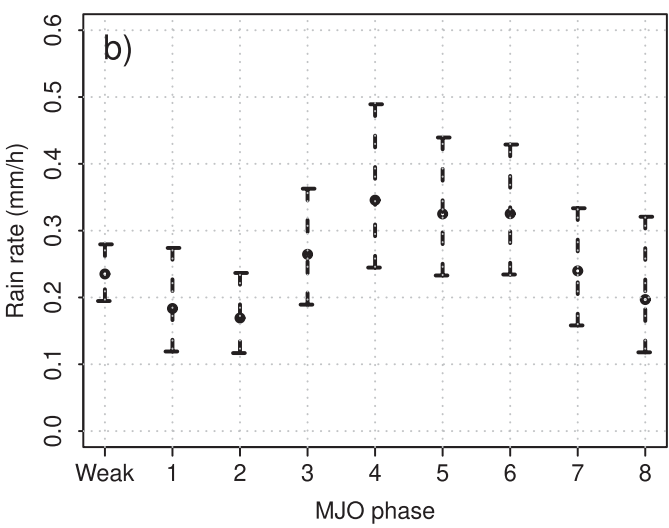

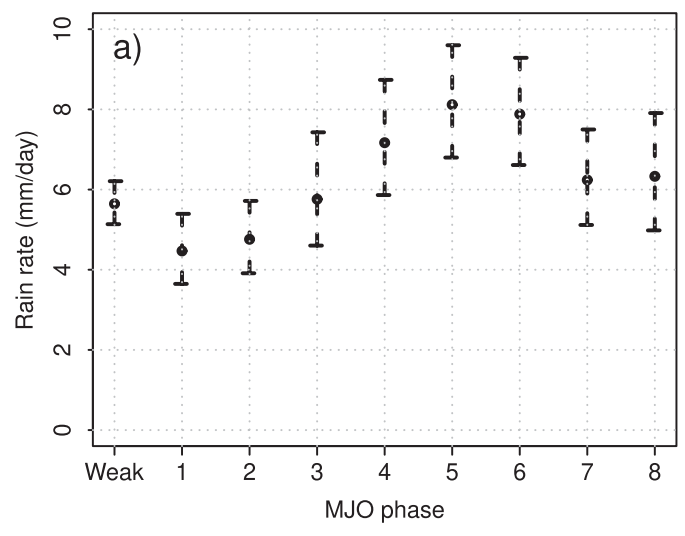

FIG. 4. (a) Daily mean rainfall $\left(\mathrm{mm} \mathrm{day}^{-1}\right)$ averaged on the 28 stations for each MJO phase. (b) Amplitude $\left(\mathrm{mm} \mathrm{h}^{-1}\right)$ of the spatially averaged composite diurnal cycle for each MJO phase. Error bars indicate the $95 \%$ confidence interval determined from a bootstrap procedure. 

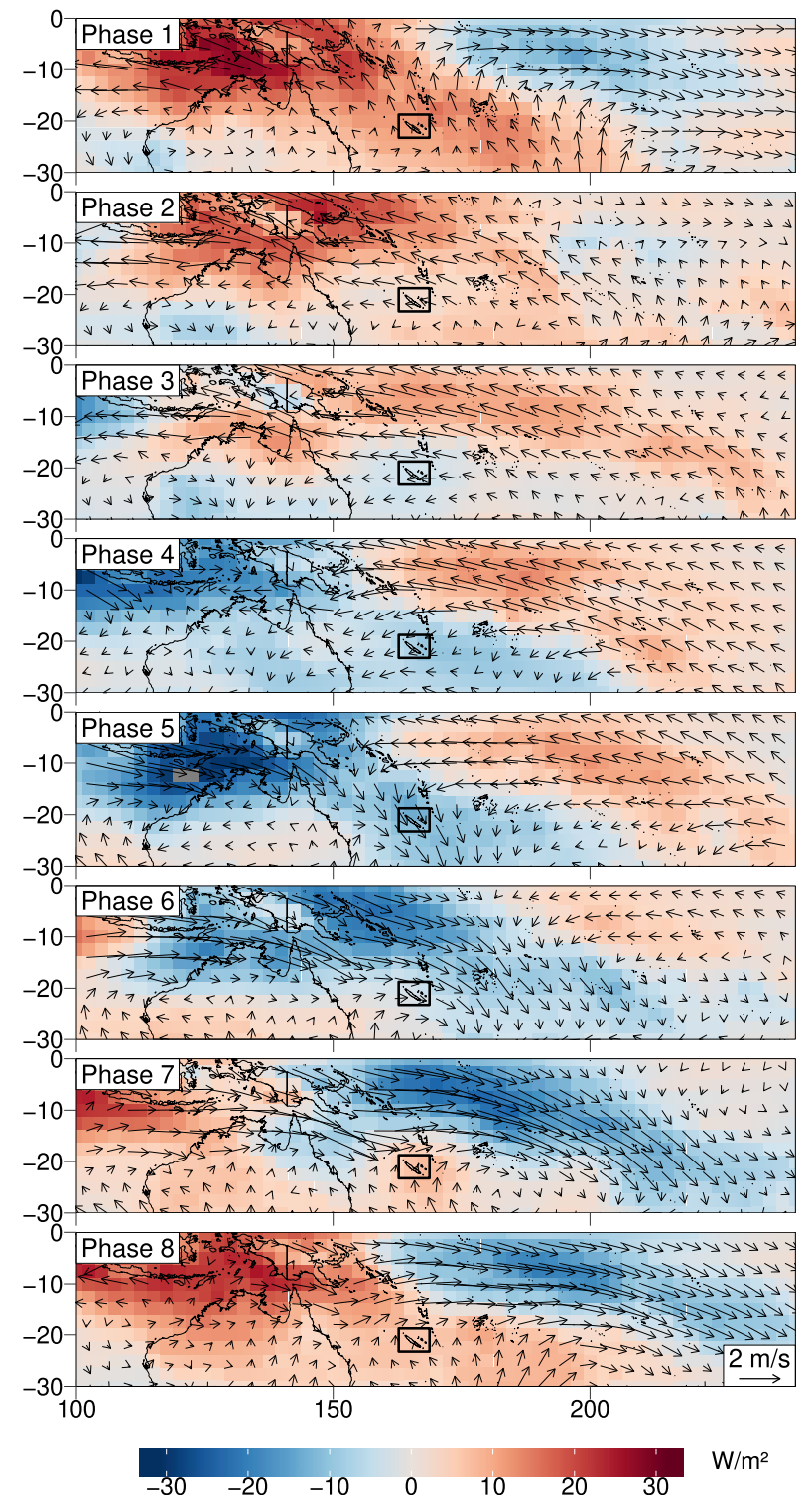

FIG. 5. NOAA OLR anomalies [OLRa as defined in Wheeler and Hendon (2004)] (shadings, in $\mathrm{W} \mathrm{m}^{-2}$ ) and 10-m wind anomalies (vectors, $\mathrm{m} \mathrm{s}^{-1}$ ) in ERA-Interim for each MJO phase. The black rectangle indicates New Caledonia's region shown in Fig. 1.

peak approximately one phase in advance compared to the mean rainfall (phase 4 versus phase 5). This is reminiscent of Peatman et al. (2014)'s results, which documented a peak in diurnal amplitude with a onephase lead before the arrival of the MJO envelope over the Maritime Continent. As for the time of the daily rainfall maximum, no significant modulation by the phase of the MJO has been observed (not shown). Therefore, the change in the timing of the afternoon peak in relation with the MJO will not be further investigated in this study.

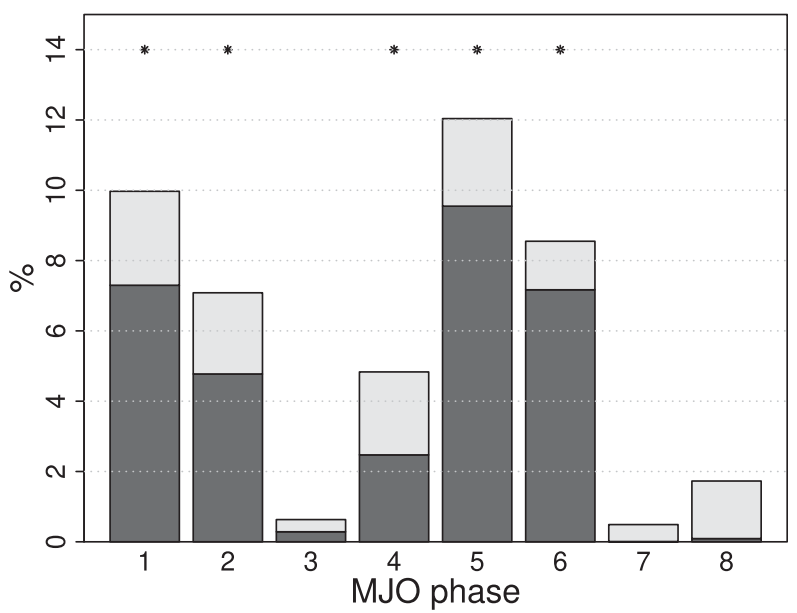

FIG. 6. Squared distance between the composite diurnal cycle for each MJO phase $\mathbf{r}_{\phi}$ (weak MJO days not included) and the mean diurnal cycle $\overline{\mathbf{r}}$ expressed as a percentage of $\|\overline{\mathbf{r}}\|^{2}$ $\left[100 \times\left(\left\|\overline{\mathbf{r}_{\phi}}-\overline{\mathbf{r}}\right\|^{2} /\|\overline{\mathbf{r}}\|^{2}\right)\right]$. The asterisks indicate distances that are significant at the $95 \%$ confidence level (see section 2c). Dark shadings: contribution from the change in daily mean. Light shadings: contribution from the change in the hourly anomalies relative to the daily mean.

The squared distance between the long-term mean diurnal cycle $\overline{\mathbf{r}}$ (as represented in Fig. 3) and the composite diurnal cycle $\mathbf{r}_{\phi}$ for a given MJO phase $\phi$ is defined in section 2c. Figure 6 shows these squared distances for each MJO phase as a fraction of the squared norm $\|\mathbf{\mathbf { r }}\|^{2}$ of the long-term mean diurnal cycle. The distances that are significant at the $95 \%$ confidence level (see section 2c) are indicated with asterisks above. The MJO phases for which the average diurnal cycle over all stations in New Caledonia is the most modified are phases $1,2,5,6$, and, to a lesser extent, 4 . This is consistent with the results on Fig. 4: phases 1 and 2 are the driest phases with little diurnal variability, while phases 4,5 , and 6 are the wettest phases with an enhanced diurnal peak. The same analysis for separate geographical zones (not shown) highlights similar impacts with only minor changes.

Following Eq. (3), the modifications of the diurnal cycle in Fig. 6 are also split into a contribution from the change in daily mean (in dark gray) and a contribution from the change in the hourly anomalies relative to the daily mean (in light gray). The modification of the diurnal cycle by the MJO appears to be primarily driven by the modification of the daily mean, while the modification of the diurnal variability only plays a secondary role. This is consistent with the results in Fig. 4 in which the impact of the MJO is clearer on the daily mean than on the diurnal amplitude. However, this decomposition neglects the influence of the diurnal cycle on the mean and the contribution from the diurnal anomalies should 


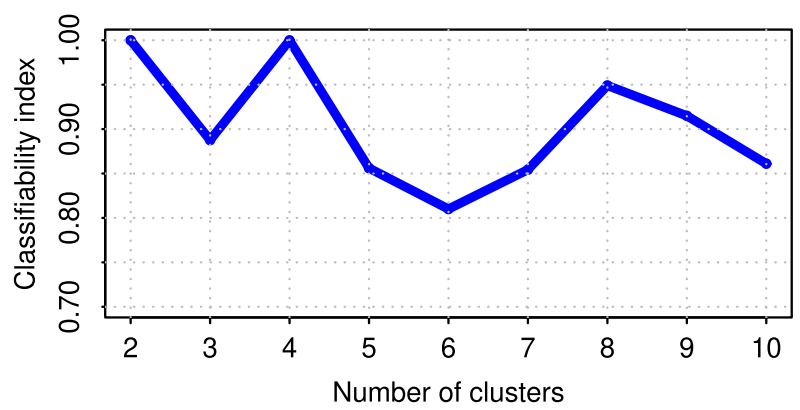

FIG. 7. Classifiability index for each number of clusters, determined from the two first PCs of ERA-Interim 10-m winds in the New Caledonia domain $\left(25^{\circ}-17^{\circ} \mathrm{S}, 161^{\circ}-170^{\circ} \mathrm{E}\right)$

be considered a lower bound of the contribution from the diurnal cycle. The contribution of the diurnal variability is noteworthy for the five MJO phases when the deviation from the long-term mean diurnal cycle is particularly significant (e.g., in phase 4).

\section{c. Identification of wind regimes}

The surface wind anomalies associated with the MJO propagation (Fig. 5) suggest an influence of the $\mathrm{MJO}$ on the circulation around New Caledonia. This is an incentive to investigate how the effect of the MJO on the diurnal cycle of rainfall over New Caledonia is mediated through the synoptic wind regimes, as in Leroy (2006), Lefèvre et al. (2010) and Moron et al. (2015). The wind regimes were determined using ERA-Interim 10-m winds as explained in section $2 \mathrm{~b}$. The computation of the classifiability index for 2 to 10 clusters is illustrated in Fig. 7. Given the excellent classifiability for four clusters which is also a reasonable number of wind regimes, four wind regimes were retained. This number is consistent with the previous findings of Leroy (2006) and Lefèvre et al. (2010), although the classifications were carried out on different datasets.

The composite wind maps for each regime are represented in Fig. 8. These regimes can be described as follows, in order of increasing average wind speed:

- Northerly regime: the flow crossing the island is slowed down on the windward side, while the wind flowing to the west remains slightly stronger. It is the least frequent regime ( $14.3 \%$ of wet-season days) and has the weakest wind speed.

- Southerly regime: the flow comes south-southeasterly and is stronger south of the island than north of it. It has a frequency of $19.3 \%$ of wet-season days.

- Easterly regime: the flow is straight from the east and slows down slightly in the island's wake. It is one of the two most common regime, with a frequency of $33.2 \%$.
- Trade wind regime: the flow is very regular, almost along the main axis of the island. This flow is very similar to, although faster than, the seasonal mean. It is the other most common regime (33.2\% of wet-season days) and it has the strongest wind speed.

Since wind regimes are supposed to represent recurrent patterns that may last for a few days, the probabilities of transition between regimes are also important additional information about their behavior. Table 1 displays these probabilities. The only transition that is significantly more probable than a random draw at the $95 \%$ confidence level is the transition from the northerly to the southerly regime. This corresponds to the eastward propagation of a cyclonic perturbation over the island. All other probabilities that are significantly more probable than a random draw are the probabilities of persistence of each regime. All other transitions are less likely than a random draw.

\section{d. Influence of the wind regimes on rainfall and its diurnal cycle}

\section{1) SPATially AVERAGED INFLUENCE}

Figure 9a displays the diurnal cycle for each regime, averaged over all 28 stations. In terms of average rainfall, the northerly regime is by far the wettest, the easterly and southerly regimes exhibit a similar, intermediate behavior, and the trade wind regime is the driest. The northerly regime can be interpreted as a southward shift of the SPCZ identified in previous studies (Lefort 2005; Leroy 2006). It corresponds to the arrival of warm, moist air from the equatorial band resulting in precipitation over the island. The difference in rainfall averages between wind regimes generally coincides with a difference in amplitude of the diurnal cycle. The afternoon peak in the northerly regime is larger in amplitude than that of the easterly and southerly regime, while the trade wind regime exhibits an even flatter cycle. Another interesting feature for the northerly regime is the secondary maximum during the night. This secondary peak is presumably due to the advection of precipitating cloud from the equatorial oceanic regions. Similar to the MJO phases (Fig. 6), the distance between the average diurnal cycle for each regime and the long-term mean diurnal cycle is illustrated in Fig. 9b. The two regimes for which there is a significant difference are the northerly and the trade regimes, that is to say the more extreme (wettest and driest) ones, in agreement with Fig. 9a.

\section{2) Spatial ClassificAtion OF RAIN GAUGE STATIONS}

The presence of a mountain range and the asymmetry in the island's mean rainfall pattern (see Fig. 2) suggests 

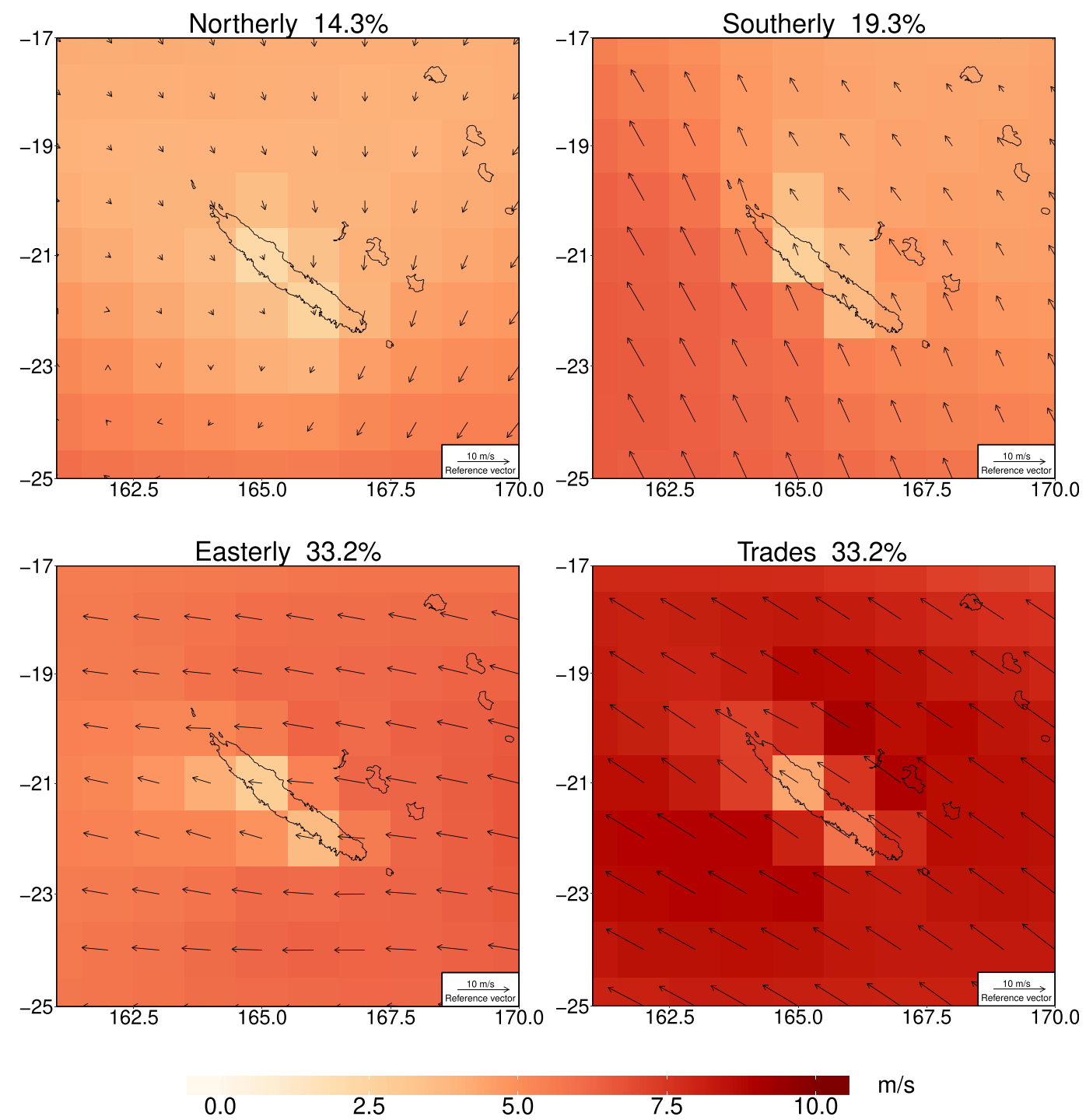

$\mathrm{m} / \mathrm{s}$

FIG. 8. Composite maps of ERA-Interim 10-m winds (arrows) and wind speed (shadings) for the four wet season regimes.

that the influence of the wind regimes on the diurnal cycle might not be the same for all stations. This matter is investigated by dividing the island into distinct geographical zones following the procedure of spatial clustering detailed in section $2 \mathrm{~d}$. The resulting dendrogram is represented in Fig. 10a. It shows that a classification into 3 geographical clusters is relevant in order to obtain distinct, well-separated clusters. The location of the stations in the 3 clusters is represented in Fig. 10b. The clustering algorithm separates the stations into geographically consistent zones: the mountain range ("Range"), the east coast ("East") and the west coast ("West"). The mountain stations of the Range can be identified by their altitude since they are higher than any other station in East or West. The smoothed, average diurnal cycles for each cluster are represented in Fig. 11. The mountain range and the east coast are both wetter than the west coast, as could be expected from Fig. 1. In terms of diurnal variability, the west coast and the mountain range exhibit a similar behavior with an afternoon peak as in the all-station average diurnal cycle (Fig. 3). On the other hand, the east coast features a flatter diurnal cycle with a minimum in the morning around $1000-1100$ and slightly more rain from the midafternoon until the end of the night.

Two hypotheses can be put forward to explain the flatter diurnal cycle in the East. First, the east coast is on the windward side most of the time so it presumably undergoes precipitation that is mostly related to the large-scale wind dynamics (cloud formation due to 
TABLE 1. (top) Probabilities of transition between wind regimes. Row: regime in day $d$. Column: regime in day $d+1$. The probabilities are expressed relative to the regime in day $d$ (rows add up to 1). Bold: transition more probable at the $95 \%$ level than in 10000 random sequences. Italics: transition less probable at the $95 \%$ level than in 10000 random sequences. (bottom) Number and average duration for each regime spell. All statistics are computed for the 1979-2017 NDJFMA period.

\begin{tabular}{lcccc}
\hline \hline & Northerly & Southerly & Easterly & Trades \\
\hline Regime transition & & & & \\
$\quad$ Northerly & $\mathbf{0 . 6 3}$ & $\mathbf{0 . 2 5}$ & 0.12 & 0 \\
Southerly & 0.06 & $\mathbf{0 . 5 9}$ & 0.14 & 0.21 \\
Easterly & 0.12 & 0.08 & $\mathbf{0 . 6 9}$ & 0.11 \\
$\quad$ Trades & 0 & 0.06 & 0.17 & $\mathbf{0 . 7 7}$ \\
Size and duration & & & & \\
$\quad$ Episodes & 374 & 565 & 735 & 557 \\
$\quad$ Duration (days) & 2.7 & 2.4 & 3.2 & 4.2 \\
\hline
\end{tabular}

orographic lifting, cloud advection from the open sea). This kind of precipitation is therefore independent from the local diurnal variability. Second, the local diurnal variability of winds and solar radiation is itself very weak on the east coast. This aspect has already been thoroughly investigated with numerical modeling by Lefèvre et al. (2010). Because of the higher mean cloud cover on the east coast, less solar radiation reaches the surface. The sea breeze then tends to be far weaker than that on the west coast due to this difference in insolation, but also to a difference in sea surface temperatures. Indeed, the sea surface temperature is also warmer off the east coast than off the west coast because New Caledonia is located at the edge of the western Pacific warm pool. This creates a smaller land/sea surface temperature contrast and a weaker sea breeze on the east coast. As a result, rainfall on the east coast shows less diurnal variations, while the west coast experiences a pronounced diurnal cycle of rainfall owing to its strong sea breeze, even if its average precipitation is lower than in the other two parts of the island. As for the mountain range, the diurnal cycle of thermal convection and the interaction with the sea breeze are likely to explain most of its strong afternoon peak.

\section{3) Geographical influence OF THE WIND REGIMES ON THE DIURNAL CYCLE}

Figure 12 shows the influence of the wind regimes for each geographical cluster of stations. The influence on rainfall in clusters Range and West (Figs. 12a,c) is very similar to the influence that is observed in Fig. 9 for the diurnal cycle averaged over all 28 stations. In other words, the rainiest regime is the northerly regime, followed by the southerly and easterly regimes, and finally by the driest trade-wind regime. The diurnal amplitude is also similarly related to the average rainfall: the rainier the regime, the larger the diurnal amplitude. However, the influence of the wind regimes on the east coast (Fig. 12b) shows an altogether different behavior. While the easterly and trade wind regimes are associated with a relatively flat diurnal cycle with a minimum in late morning, the northerly and southerly regimes differ significantly from the average east coast diurnal cycle (Fig. 11). The southerly regime, that is quite dry on the east coast, exhibits a diurnal variability with a marked afternoon peak. The northerly regime is also characterized by a similar afternoon peak and by another secondary peak at the end of the night that has already been identified in Fig. 9.

We can propose a few tentative explanations for the specific behavior of the diurnal cycle on the east coast in the southerly and northerly regimes, although the
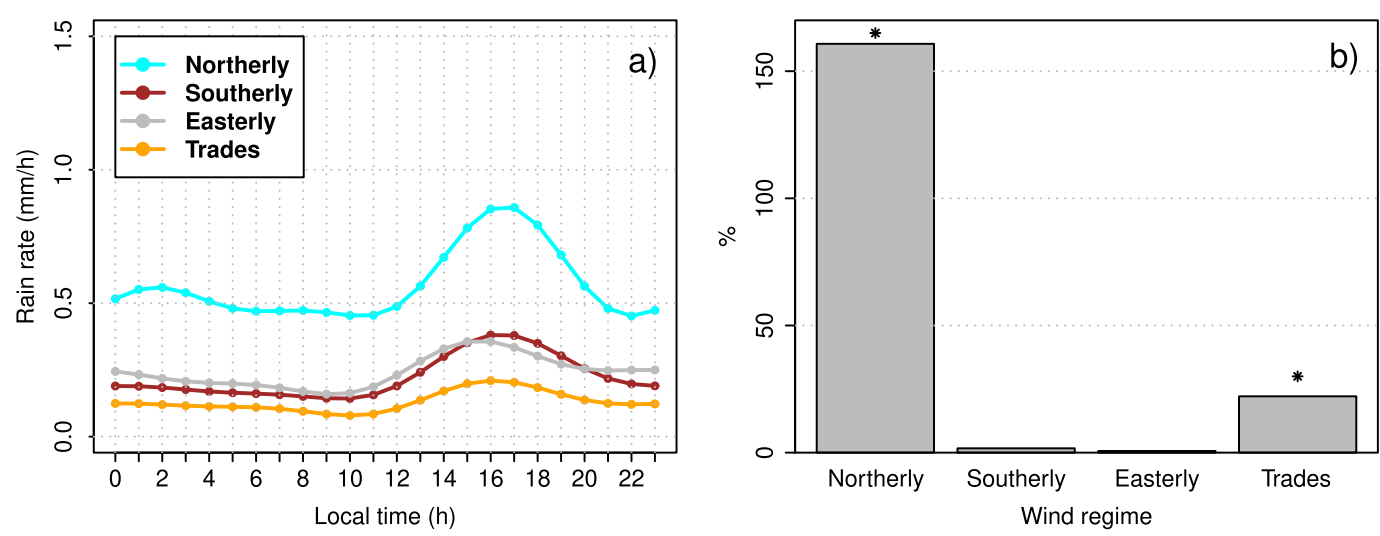

FIG. 9. (a) Spatially averaged diurnal cycle of rainfall for each wind regime $\left(\mathrm{mm} \mathrm{h}^{-1}\right)$. (b) Squared distance between the composite diurnal cycle for each wind regime $\mathbf{r}_{\mathbf{i}}$ and the mean diurnal cycle $\overline{\mathbf{r}}$ expressed as a percentage of $\|\overline{\mathbf{r}}\|^{2}\left[100 \times\left(\left\|\overline{\mathbf{r}_{\mathbf{i}}}-\overline{\mathbf{r}}\right\|^{2} /\|\overline{\mathbf{r}}\|^{2}\right)\right]$. The asterisks indicate distances that are significant at the $95 \%$ confidence level (see section $2 \mathrm{c}$ ). 

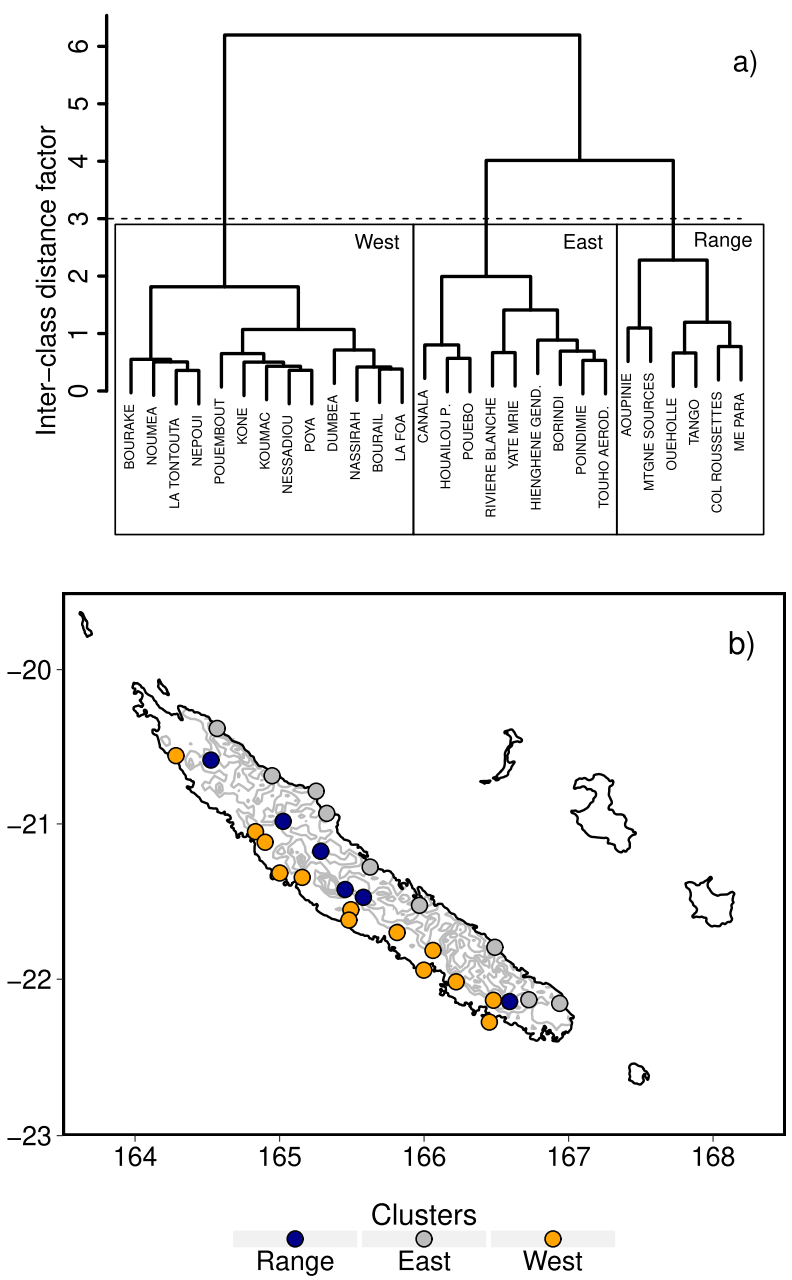

FIG. 10. (a) Dendrogram of the hierarchical clustering of the 28 rain gauge stations. (b) Location of the 3 clusters retained with elevation levels indicated by gray lines.

mechanisms that explain this sensitivity would deserve a thorough investigation that is beyond the scope of this article. In section $3 \mathrm{~d}(2)$, two hypotheses have been put forward to explain the flatter average diurnal cycle on the east coast: the continuous rainfall due to large-scale dynamics, and the weaker insolation and sea-breeze diurnal variability. These hypotheses are strongly linked to the fact the east coast is the average windward coast. In the southerly regime, however, the east coast becomes the leeward coast. Sheltered by the mountain range, a sea-breeze circulation can develop and the absence of clouds favors a diurnal cycle of surface heating and afternoon convection. As a result, the diurnal cycle of rainfall on the east coast in the southerly regime exhibits an afternoon peak similar to the diurnal cycle on the west coast in the easterly regime. During the northerly regime, very weak winds and high humidity generally enhance the diurnal cycle of convection all

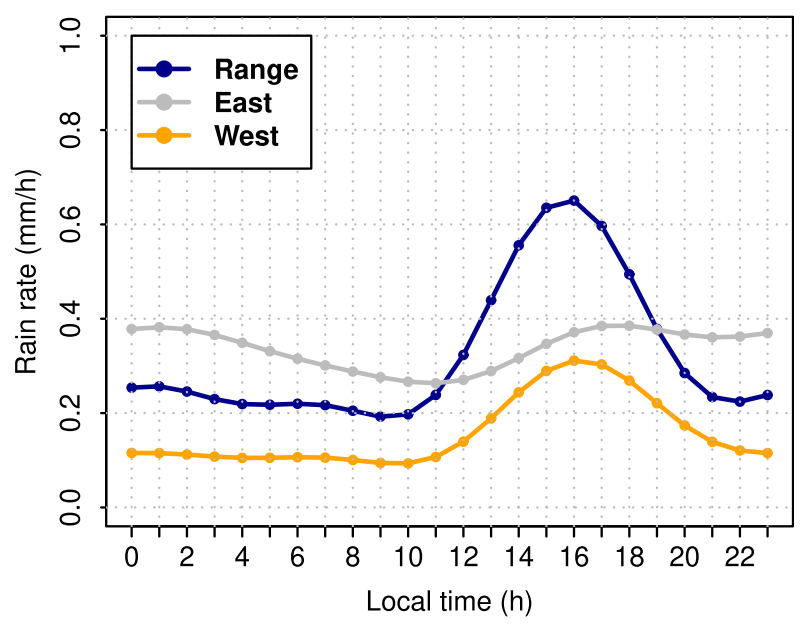

FIG. 11. Diurnal cycles of rainfall $\left(\mathrm{mm} \mathrm{h}^{-1}\right)$ for each geographical zone.

over the island and the east coast is also affected, hence the afternoon peak it also exhibits in this case. The secondary nocturnal peak, on the other hand, can be attributed to the advection of precipitating clouds from oceanic regions further north.

\section{MJO impact on the diurnal cycle via wind regimes}

The findings in section 3 illustrate separately the impact of the MJO and wind regimes on the diurnal cycle. These two points can be linked, first by considering the influence of the MJO on the wind regimes, and next by considering whether the MJO influence on the diurnal cycle of rainfall is mediated by the wind regimes.

\section{a. Frequency variability of wind regimes with the $M J O$}

We first investigate whether the MJO influences the frequency of occurrence of the wind regimes, in line with Model 1 introduced in section 2f. Following the methodology described in section 2e, we perform a statistical analysis of these frequencies of occurrence in the eight MJO phases. Table 2 shows the $p$ values of the chi-square test applied separately for each regime. The $p$ value is always less than $5 \%$, which enables to reject the null hypothesis that the regime frequencies do not depend on the MJO phase. Table 3 indicates the percentage of the regimes per MJO phase. Percentages corresponding to a significantly more frequent regime within the MJO phase (according to the values of Pearson's residuals) are in bold, those corresponding to a significantly less frequent regime are in italics.

A striking fact from Table 3 is that the easterly, northerly and southerly regimes seem to succeed each 


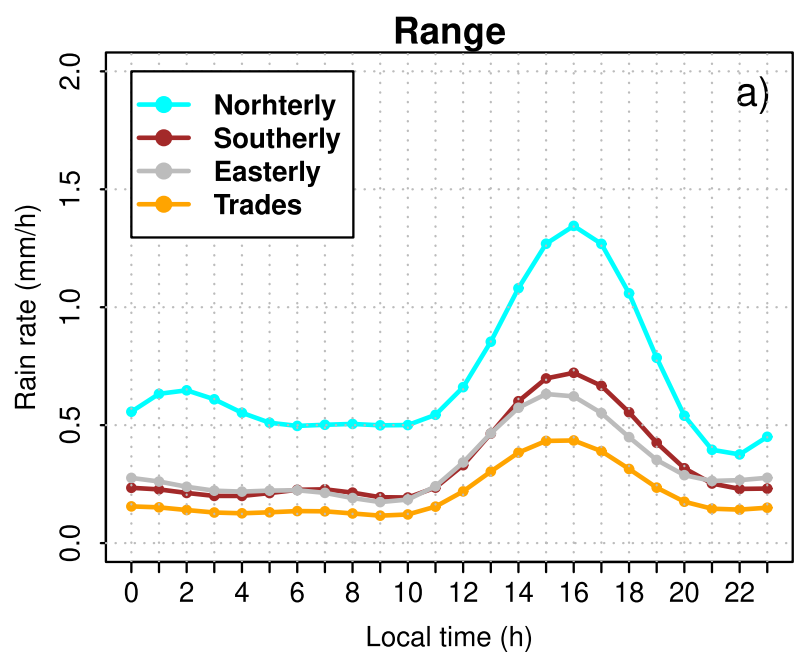

East
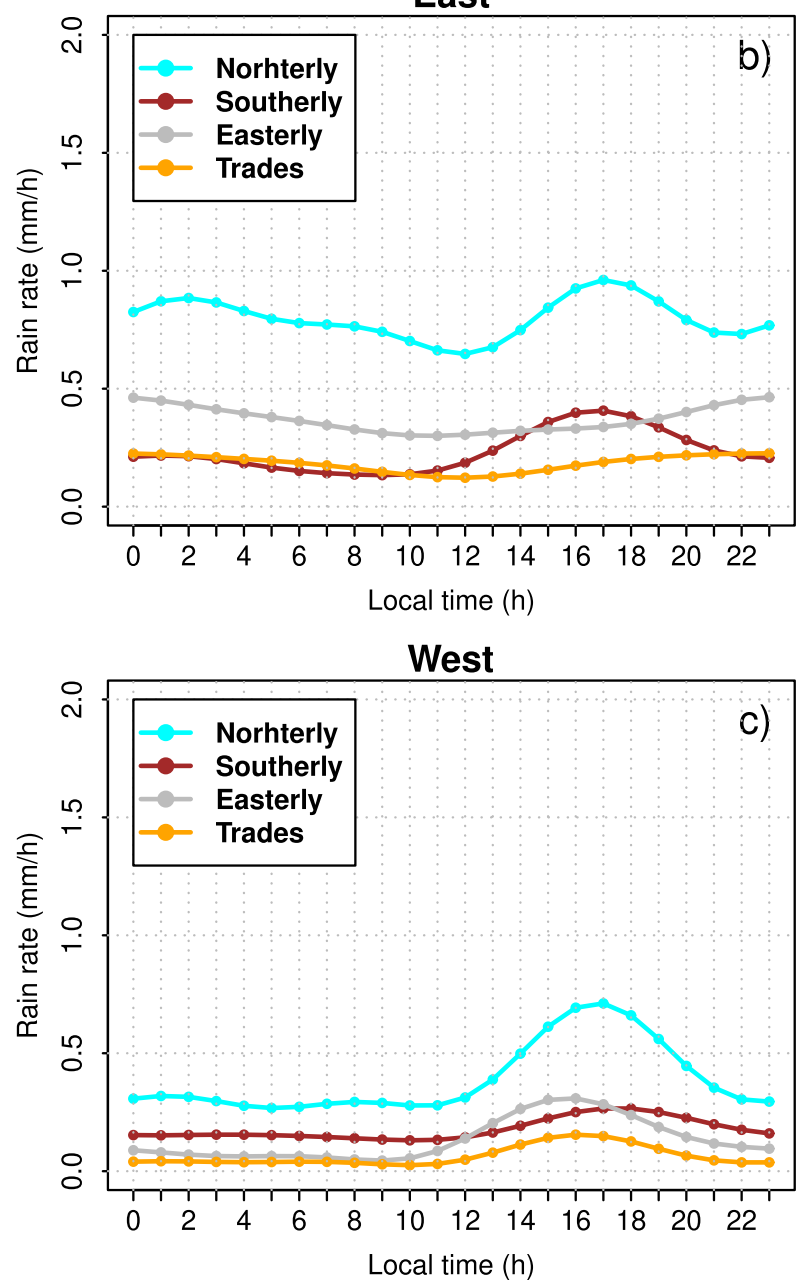

FIG. 12. Spatially averaged diurnal cycle of rainfall for each wind regime $\left(\mathrm{mm} \mathrm{h}^{-1}\right)$ : (a) mountain range, (b) east coast, and (c) west coast.
TABLE 2. The $p$ value of the $\chi^{2}$ test assessing the distribution of each wind regime among the MJO phases (weak MJO included).

\begin{tabular}{ccccc}
\hline \hline & Northerly & Southerly & Easterly & Trades \\
\hline$p$ value & 0 & $1.2 \times 10^{-6}$ & $1.6 \times 10^{-11}$ & $1.8 \times 10^{-4}$
\end{tabular}

other in the MJO cycle in terms of overrepresentation. Indeed, the easterly regime occur significantly more frequently in phases 2,3 , and 4 , when the MJO convective envelope is still in the Indian Ocean or over the Maritime Continent. On the contrary, it is significantly less frequent in phases 6,7 , and 8 when the convective envelope is over the Central Pacific or weak and further east. The northerly regime occurs significantly less frequently in the phases 1,2 , and 3 when convection is suppressed over New Caledonia, and it occurs significantly more frequently in the wettest phases 5 and 6 . As for the southerly regime, it is also significantly less frequent in the dry phases 2 and 3 and significantly more frequent in phase 6 . Trade winds are frequent in all phases, except in the phases 5 and 6 of intensified convection over New Caledonia, when they are significantly less frequent. These findings are in agreement with the wind anomalies associated to the MJO phases as represented in Fig. 5. In phases 2 and 3, New Caledonia experiences easterly MJO low-level wind anomalies. These MJO anomalies rotate counterclockwise around New Caledonia with the succession of phases: they have a northeasterly orientation in phase 4 , a northerly orientation in phase 5 , a westerly orientation in phase 6 and a southerly orientation in phase 7 . In phases 8 and 1, which are phases for which the MJO is less active over New Caledonia, the anomalies are southeasterly, with the same orientation as the climatological trade winds. Considering these observations and the transition probabilities in Table 1, it can be deduced that there is a sequence of wind regimes (easterly $\rightarrow$ northerly $\rightarrow$ southerly) that is due to the propagation of the MJO wind anomalies. This sequence will not necessarily be observed exactly for every MJO event, because fast intraseasonal and synoptic variability allow all regimes to occur in all phases, but it corresponds to a canonical evolution that the atmosphere tends to follow during such events. It is typical of the MJO dynamical signature (Rui and Wang 1990; Zhang 2005), with easterly winds east of the convective signal and two off-equatorial cyclonic gyres propagating along with the equatorial convective center. The southern gyre is responsible for the wind anomalies around New Caledonia, with a northerly component when New Caledonia is in the poleward branch of the gyre and a southerly component when it is in the equatorward branch. 
TABLE 3. Percentage of wind regimes by MJO phase. Bold: the regime is significantly more frequent in the phase (Pearson's residual greater than +2 ). Italics: the regime is significantly less frequent in the MJO phase (Pearson's residual less than -2 ).

\begin{tabular}{lcrrrrrrrrr}
\hline \hline MJO phase & Total & \multicolumn{1}{c}{1} & \multicolumn{1}{c}{2} & \multicolumn{1}{c}{3} & 4 & 5 & 6 & 7 & 8 & Weak MJO \\
\hline Northerly & 14.3 & 9.3 & 5.5 & 8.4 & 11.5 & $\mathbf{2 4 . 0}$ & $\mathbf{2 0 . 6}$ & 16.8 & 15.2 & 14.8 \\
Southerly & 19.3 & 23.0 & 14.4 & 14.7 & 15.8 & 15.7 & $\mathbf{2 6 . 1}$ & 22.0 & 21.6 & 19.5 \\
Easterly & 33.2 & 30.4 & $\mathbf{4 4 . 0}$ & $\mathbf{3 9 . 5}$ & $\mathbf{4 2 . 5}$ & 34.0 & 27.9 & 25.0 & 27.0 & 32.3 \\
Trades & 33.2 & 37.3 & 36.1 & 37.4 & 30.2 & 26.3 & 25.4 & 36.2 & 36.2 & 33.4 \\
\hline
\end{tabular}

\section{b. How does the interaction between MJO and wind regimes impact the diurnal cycle?}

As seen in Figs. 4 and 6, the MJO modifies the diurnal cycle of precipitation over New Caledonia during its most active and suppressed phases. As for wind regimes, Figs. 8 and 11 also demonstrate their impact on the diurnal cycle. How do these two large-scale influences interact? And how does this interaction help understand the impact of the MJO on the diurnal cycle? The decomposition of the anomalous diurnal cycles proposed in section $2 \mathrm{f}$ with two simple models, for the particular case where the number of wind regimes is $N_{w}=4$, is used to answer these questions.

The contributions of the 9 terms in the squared distance to the long-term mean diurnal cycle, detailed in Eq. (16), are represented in Fig. 13. According to Fig. 6, the deviations from the long-term mean diurnal cycle are weak for phases 3,7, and 8 . Consequently, Fig. 13 only represents the decomposition for the five other MJO phases (1, 2, 4, 5, and 6). The contributions are shown as fractions of $\|\overline{\mathbf{r}}\|^{2}$ in the same way as in Fig. 6. The first four bars correspond to the $f_{i \phi}\left\langle\mathbf{r}_{\phi}^{\prime} \mid \mathbf{r}_{\mathbf{i}}^{\prime}\right\rangle$ terms for each regime, associated with Model 1 and which we will call frequency change terms, and their sum is indicated by the first background gray bar. The next four bars correspond to the $f_{i}\left\langle\mathbf{r}_{\phi}^{\prime} \mid \mathbf{r}_{\mathbf{i} \phi}-\mathbf{r}_{\mathbf{i}}\right\rangle$ terms associated with Model 2 and which we will call regime change terms, and their sum is also represented in the background. The gray bar on the right indicates the value of the residual term $\mathbf{s}$. Note that all these terms correspond to the decomposition of the overall distances represented in Fig. 6, without separating between the daily mean and the diurnal anomalies relative to the daily mean. The same decomposition has been carried out for these two components separately (not shown). According to Fig. 6, the change in daily mean accounts for most of the changes in the diurnal cycle. As a result, when the decomposition in Eq. (16) is carried out on the daily mean only, the results are similar as those in Fig. 13, while the contributions related to the diurnal anomalies are less prominent. The results in Fig. 13 are therefore mostly interpreted in terms of modification of the daily mean.
The contributions of frequency changes $f_{i \phi}\left\langle\mathbf{r}_{\phi}^{\prime} \mid \mathbf{r}_{\mathbf{i}}^{\prime}\right\rangle$, associated with Model 1, need to be considered with caution. They tend to attribute prominent contributions to the northerly and trade wind regimes because the average diurnal cycles of these regimes are the most different to the long-term mean diurnal cycle, as shown in Fig. 9b. When one of these two regimes is less represented than usual, its contribution $f_{i \phi}\left\langle\mathbf{r}_{\phi}^{\prime} \mid \mathbf{r}_{\mathbf{i}}^{\prime}\right\rangle$ will be negative: the decrease in frequency contributes to decreasing the deviation $\left\|\mathbf{r}_{\phi}^{\prime 2}\right\|^{2}$ from the long-term mean diurnal cycle in phase $\phi$. On the contrary, when one of these two regimes is more frequent than usual, the same contribution will be positive and increase the deviation to the long-term mean diurnal cycle. Moreover, owing to the propagation of the MJO, the frequency of these two regimes tend to vary in opposite ways. For instance, in phases 1 and 2, the northerly regime is less frequent and the trade wind regime is more frequent, while the contrary can be observed in phases 4,5 , and 6 . As a result, the contributions of the frequencies of the trade and northerly regimes tend to compensate each other partially (phases 1 and 2) or completely (phase 4 and phases 3,7 , and 8 not shown). In the case of a partial compensation, an additional compensation by the residual term can also be noted. Therefore, except for phases 5 and 6 , during which the change in frequency of the northerly regime appears to play an important role due its significant overrepresentation (see Table 3), the frequency change terms include systematic strong compensating effects and are not as physically meaningful as the regime change terms.

Phases 1 and 2 (Fig. 13, first and second panels) exhibit a similar behavior: the dominant term in the modification of the diurnal cycle is the change in diurnal cycle for the northerly regime $f_{\text {north }}\left\langle\mathbf{r}_{\phi}^{\prime} \mid \mathbf{r}_{\text {north }, \phi}-\mathbf{r}_{\text {north }}\right\rangle$, associated with Model 2. According to Fig. 5, these phases correspond to large-scale conditions that are not favorable for convection. Then, the northerly regime, which is supposed to be the wettest regime cannot be as wet as usual, hence the influence of the modification of its diurnal cycle in the overall changes. This contribution is positive: the change in the diurnal cycle of the northerly regime increases the difference between the diurnal cycles of phases 1 and 2 and the long-term mean diurnal 

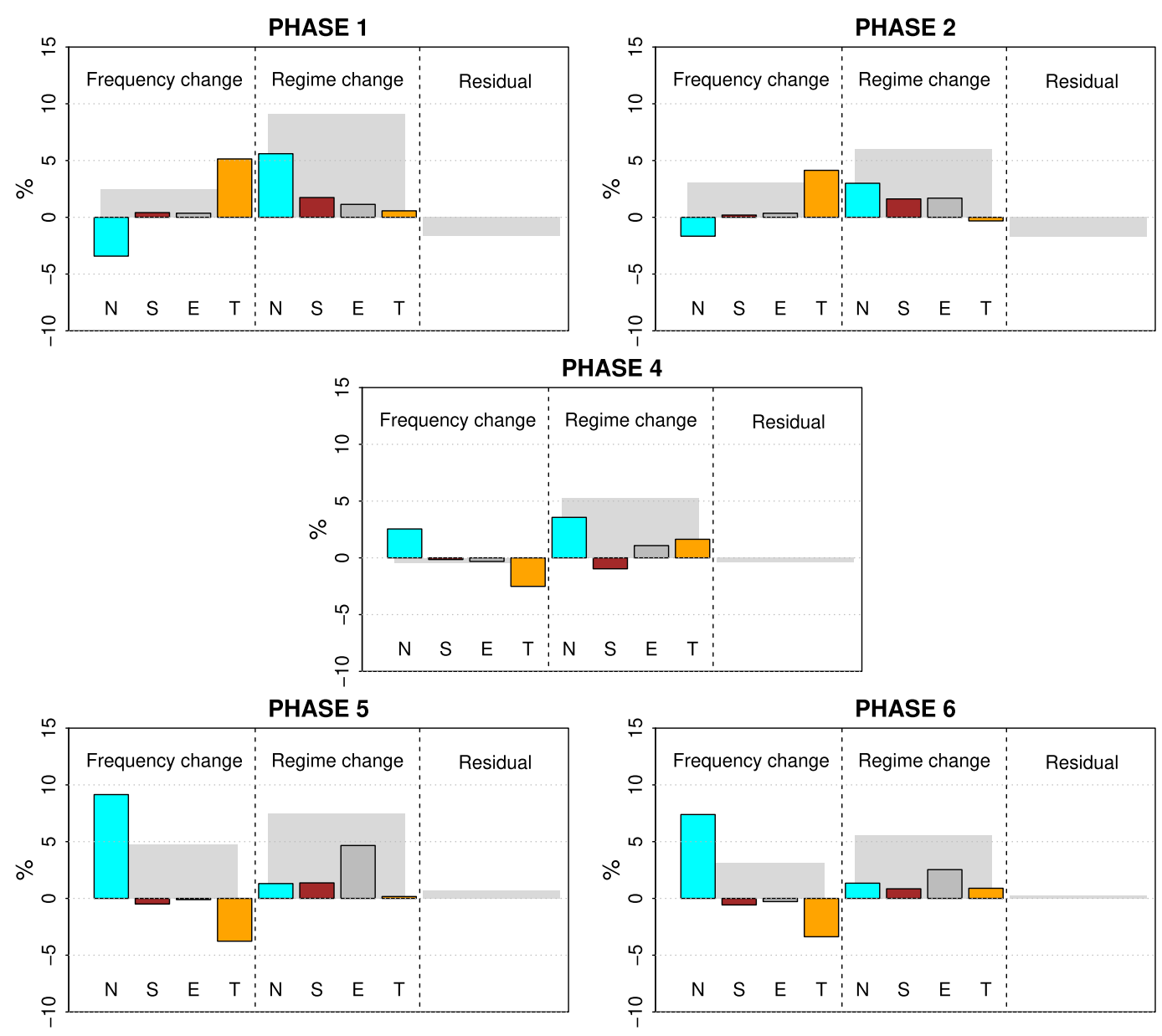

FIG. 13. Decomposition of the squared distances between the MJO composite cycles $\mathbf{r}_{\phi}$ and the long-term mean diurnal cycle $\overline{\mathbf{r}}$ as a percentage of $\|\overline{\mathbf{r}}\|^{2}$, according to Eq. (16). The first four terms represent the contribution of regime frequency changes, the next four terms the contribution of regime change at constant frequency. $\mathrm{N}$ : northerly regime. S: southerly regime. E: easterly regime. T: trade winds regime.

cycle. Similar contributions can be observed, to a lesser extent, for the southerly and easterly regimes. Therefore, the diurnal cycle modification for MJO phases 1 and 2 is mostly a matter of unfavorable large-scale conditions for convection that impact almost all regimes but have the most important effect on the regime with the strongest diurnal cycle. MJO phase 4 (Fig. 13, third panel) is also characterized by a positive contribution from the change in the northerly regime diurnal cycle associated with Model 2. However, unlike MJO phases 1 and 2, in MJO phase 4 convection intensifies over New Caledonia and as a result the diurnal cycle in the northerly regime is enhanced. A secondary contribution from the diurnal cycle of the trade-wind regime $f_{\text {trades }}\left\langle\mathbf{r}_{\phi}^{\prime} \mid \mathbf{r}_{\text {trades }, \phi}-\mathbf{r}_{\text {trades }}\right\rangle$ is also significant, while the effects of the easterly and southerly regimes compensate. The diurnal cycle is enhanced in the northerly regime in MJO phase 4 compared to the all-phase northerly regime composite, and this can be explained by three factors: the favorable large-scale conditions for convection mentioned above, the moister air that is brought by the northerly regime, but also the weaker wind speed in this regime. Indeed, results from previous work tend to demonstrate that all other conditions being identical, the diurnal cycle will be stronger when low-level wind is weak (Wang and Sobel 2017). Finally, phases 5 and 6, as mentioned previously, are dominated by a significant effect of the change in the northerly regime frequency $f_{\text {north, } \phi}\left\langle\mathbf{r}_{\phi}^{\prime} \mid \mathbf{r}_{\text {north }}^{\prime}\right\rangle$ that is not entirely compensated by the change in the trade regime frequency or by the residual term. This is in agreement with the findings by Moron et al. (2016, Fig. 12), for which the wettest rainfall regime, associated with a southwestward shifted SPCZ and prevalent northerly winds, also has its frequency strongly modulated by subseasonal variability. Here, the increase in northerly regime frequency in phases 5 and 6 
can be held partially responsible for the intensification of the diurnal cycle, along with changes in the diurnal cycle for the easterly regime $f_{\text {east }}\left\langle\mathbf{r}_{\phi}^{\prime} \mid \mathbf{r}_{\text {east }, \phi}-\mathbf{r}_{\text {east }}\right\rangle$. The easterly regime exhibits an enhanced diurnal cycle in phases 5 and 6 owing to its orientation that is shifted northeasterly, its weaker speed and, again, the favorable large-scale conditions for convection. These different interactions between the MJO and the wind regimes have been considered for the diurnal cycle averaged on all stations. Qualitatively similar results can be found separately for the three geographical groups of stations (Range, East, and West) identified in section $3 \mathrm{~d}$ (not shown).

\section{Summary and discussion}

This study demonstrates that the Madden-Julian oscillation is associated with rainfall anomalies in New Caledonia that can be noted mostly in the daily average but also, to a lesser extent, in the diurnal variability. These two components are in fact closely entangled together when it comes to modulation by the MJO because the variations in the diurnal amplitude result in variations in the daily mean. MJO phases 1 and 2 are responsible for a weaker diurnal cycle while it is enhanced in phases 4,5 , and 6 . The link between the largescale intraseasonal variability and the local-scale diurnal cycle of rainfall is established through the use of wind regimes as an intermediate tool. Four regimes were identified to classify the surface wind circulation in a small domain encompassing New Caledonia. They are also associated with differences in the rainfall average and in the diurnal cycle, depending on where the air masses come from and how they interact with the island's topography. Owing to this complex topography, the island can also be objectively separated into three distinct geographical zones that exhibit differences in rainfall amounts and diurnal cycles: the mountain range, the east coast and the west coast. The diurnal cycle in these zones might be subject to quantitative but also qualitative changes depending on the regime, the most notable ones being for the east coast during the northerly and southerly regimes.

From a statistical point of view, the MJO appears to modulate the probability of occurrence of the wind regimes. Its propagation brings about a counterclockwise rotation of surface wind anomalies around New Caledonia that is suggestive of an easterly-northerlysoutherly sequence. This sequence is also discernible in the frequencies of occurrence of the wind regimes within the MJO phases, some regimes being significantly more frequent in some phases while the others are significantly less frequent. However, this undeniable relationship does not necessarily mean that the influence of the MJO on the diurnal cycle of precipitation is entirely mediated by the change in frequency of wind regimes. Indeed, Moron et al. (2016, see Fig. 12) also highlight the limitations of the frequentist interpretation for the influence of subseasonal variability when it comes to rainfall itself, except for the wettest days.

This is why this study proposes a framework to assess the different contributions to the sensitivity of the diurnal cycle to the MJO. This framework consists in a decomposition into 1) terms associated with the modification of the frequency of occurrence of the wind regimes by the $\mathrm{MJO}$, and 2) terms due to changes of the characteristics of the wind regimes within the phases of the MJO. It shows that the modification of the regimes' diurnal cycle of precipitation due to the MJO (Model 2) eventually proves to account for the largest part of the MJO diurnal cycle anomalies, and that the modification of regime frequencies (Model 1) plays a lesser role. This raises the question of how the MJO brings changes in the wind regimes' diurnal cycles. We can provide several hypotheses which would require further examination. First, the MJO-induced large-scale convective conditions (enhanced, neutral or suppressed) might have different effects on the different regimes but are not directly related to the wind patterns. Second, the regime circulation anomalies in a given MJO phase are presumably involved through modifications of the wind orientation and/or speed.

The application of this framework for New Caledonia therefore highlights complex interactions that go far beyond the simple model assuming that the MJO mostly modulates the frequencies of wind regimes, contrary to what was previously expected considering past work on other regions (Ichikawa and Yasunari 2008; Hopuare et al. 2019). The complexity of these interactions even suggests that other tools besides wind regimes should be considered in order to fully decompose and understand the MJO signal that impacts New Caledonia at a local scale.

Acknowledgments. We acknowledge support from the Pacific Fund of the Ministère des Affaires Étrangères (France) through the research program PLUVAR. All data analysis in this study was performed using the open source language R. The clustering algorithms were carried out with the functions "kmeans" and "hclust" from the R base package "stats." MJO RMM values were obtained from the Australian Bureau of Meteorology: http://www.bom.gov.au/ climate/mjo/graphics/rmm.74toRealtime.txt. We would also like to thank the two anonymous reviewers whose comments helped improve this study. 
TABLE A1. List of Météo-France rain gauge stations and coordinates.

\begin{tabular}{|c|c|c|c|c|c|}
\hline Station & Start date & End date & Lon $\left({ }^{\circ} \mathrm{E}\right)$ & Lat $\left({ }^{\circ} \mathrm{S}\right)$ & Alt (m) \\
\hline AOUPINIE & 1 Jan 1991 & 31 Dec 2014 & 165.2853 & 21.177 & 905 \\
\hline BORINDI & 8 Jan 1992 & 31 Dec 2014 & 166.4915 & 21.7963 & 5 \\
\hline BOURAIL & 11 Jun 1997 & 31 Dec 2014 & 165.4938 & 21.5548 & 25 \\
\hline BOURAKE & 13 Dec 2000 & 31 Dec 2014 & 165.9998 & 21.9425 & 53 \\
\hline CANALA & 15 Jun 1993 & 30 Dec 2014 & 165.9692 & 21.5263 & 35 \\
\hline COL ROUSSETTES & 1 Jun 1999 & 31 Dec 2014 & 165.454 & 21.4233 & 361 \\
\hline DUMBEA & 4 Feb 1998 & 31 Dec 2014 & 166.4808 & 22.1357 & 14 \\
\hline HIENGHENE GEND. & 1 Feb 1994 & 31 Dec 2014 & 164.9495 & 20.6883 & 22 \\
\hline HOUAILOU P. & 1 Jan 1993 & 31 Dec 2014 & 165.628 & 21.2783 & 11 \\
\hline KONE & 1 Jul 1995 & 31 Dec 2014 & 164.8335 & 21.0513 & 9 \\
\hline KOUMAC & 15 Nov 1993 & 31 Dec 2014 & 164.2842 & 20.5587 & 25 \\
\hline LA FOA & 15 Dec 1995 & 31 Dec 2014 & 165.8147 & 21.7013 & 12 \\
\hline LA TONTOUTA & 1 Jan 1996 & 31 Dec 2014 & 166.2223 & 22.0173 & 37 \\
\hline NASSIRAH & 13 Sep 1999 & 31 Dec 2014 & 166.0632 & 21.815 & 52 \\
\hline NEPOUI & 1 Apr 1990 & 31 Dec 2014 & 165.0022 & 21.3182 & 82 \\
\hline NESSADIOU & 1 May 1991 & 31 Dec 2014 & 165.4802 & 21.6205 & 2 \\
\hline NOUMEA & 1 Jan 1996 & 31 Dec 2014 & 165.4528 & 22.276 & 70 \\
\hline OUEHOLLE & 11 Jul 1996 & 1 Dec 2008 & 164.525 & 20.588 & 155 \\
\hline POINDIMIE & 1 Jan 1993 & 31 Dec 2014 & 165.328 & 20.9325 & 14 \\
\hline POUEBO & 1 May 1992 & 6 Jun 2011 & 164.587 & 20.3982 & 13 \\
\hline POUEMBOUT & 3 Apr 1992 & 19 Feb 2009 & 164.9013 & 21.1195 & 27 \\
\hline POYA & 1 Jun 1999 & 31 Dec 2014 & 165.157 & 21.3453 & 7 \\
\hline RIVIERE BLANCHE & 6 Dec 2000 & 31 Dec 2014 & 166.7263 & 22.1327 & 171 \\
\hline TANGO & 1 Mar 1998 & 31 Dec 2014 & 165.0262 & 20.9837 & 341 \\
\hline TOUHO AEROD. & 1 Jan 1993 & 31 Dec 2014 & 165.2545 & 20.7893 & 2 \\
\hline YATE MRIE & 1 Jan 1993 & 31 Dec 2014 & 166.939 & 22.1565 & 25 \\
\hline
\end{tabular}

\section{APPENDIX}

\section{Rain Gauge Station Information}

Table A1 lists the main characteristics (location, altitude, and recording period) of the rain gauge stations where precipitation data used in this study were measured.

\section{REFERENCES}

Barbero, R., V. Moron, M. Mangeas, M. Despinoy, and C. Hély, 2011: Relationships between MODIS and ATSR fires and atmospheric variability in New Caledonia (SW Pacific). J. Geophys. Res., 116, D21110, https://doi.org/ 10.1029/2011JD015915.

Birch, C. E., S. Webster, S. C. Peatman, D. J. Parker, A. J. Matthews, Y. Li, and M. E. E. Hassim, 2016: Scale interactions between the MJO and the western Maritime Continent. J. Climate, 29, 24712492, https://doi.org/10.1175/JCLI-D-15-0557.1.

Chen, S. S., and R. A. Houze, 1997: Diurnal variation and life-cycle of deep convective systems over the tropical Pacific warm pool. Quart. J. Roy. Meteor. Soc., 123, 357-388, https://doi.org/ 10.1002/qj.49712353806.

Cronin, T. W., K. A. Emanuel, and P. Molnar, 2015: Island precipitation enhancement and the diurnal cycle in radiativeconvective equilibrium: Island rainfall enhancement in radiative-convective equilibrium. Quart. J. Roy. Meteor. Soc., 141, 1017-1034, https://doi.org/10.1002/qj.2443.

Government de la Nouvelle-Calédonie, G., 2016: Dossier sur les risques majeurs de la Nouvelle-Calédonie. Direction de la Sécurité Civile et de la Gestion des Risques de la
Nouvelle-Calédonie, accessed 20 November 2019, https:// securite-civile.nc/documents/dossier-sur-les-risques-majeurs-dela-nouvelle-caledonie.

Dee, D. P., and Coauthors, 2011: The ERA-Interim reanalysis: Configuration and performance of the data assimilation system. Quart. J. Roy. Meteor. Soc., 137, 553-597, https://doi.org/ 10.1002/qj.828.

Griffiths, G. M., M. J. Salinger, and I. Leleu, 2003: Trends in extreme daily rainfall across the South Pacific and relationship to the South Pacific Convergence Zone. Int. J. Climatol., 23, 847869, https://doi.org/10.1002/joc.923.

Hidayat, R., and S. Kizu, 2009: Influence of the Madden-Julian Oscillation on Indonesian rainfall variability in austral summer. Int. J. Climatol., 30, 1816-1825, https://doi.org/ 10.1002/joc.2005.

Hopuare, M., M. Guglielmino, and P. Ortega, 2019: Interactions between intraseasonal and diurnal variability of precipitation in the South Central Pacific: The case of a small high island, Tahiti, French Polynesia. Int. J. Climatol., 39, 670-686, https:// doi.org/10.1002/joc.5834.

Ichikawa, H., and T. Yasunari, 2008: Intraseasonal variability in diurnal rainfall over New Guinea and the surrounding oceans during austral summer. J. Climate, 21, 2852-2868, https:// doi.org/10.1175/2007JCLI1784.1.

Kanamori, H., T. Yasunari, and K. Kuraji, 2013: Modulation of the diurnal cycle of rainfall associated with the MJO observed by a dense hourly rain gauge network at Sarawak, Borneo. J. Climate, 26, 4858-4875, https://doi.org/10.1175/ JCLI-D-12-00158.1.

Kikuchi, K., and B. Wang, 2008: Diurnal precipitation regimes in the global Tropics. J. Climate, 21, 2680-2696, https://doi.org/ 10.1175/2007JCLI2051.1. 
Lefèvre, J., P. Marchesiello, N. C. Jourdain, C. Menkes, and A. Leroy, 2010: Weather regimes and orographic circulation around New Caledonia. Mar. Pollut. Bull., 61, 413-431, https:// doi.org/10.1016/j.marpolbul.2010.06.012.

Lefort, T., 2005: Starting up medium-range forecasting for New Caledonia in the South-West Pacific Ocean-A not so boring tropical climate. ECMWF Newsletter, No. 102, ECMWF, Reading, United Kingdom, 2-7.

Leroy, A., 2006: Utilisation des Prévisions Saisonnières en NouvelleCalédonie. Note de la DP 6, Météo-France, 171 pp.

- and M. C. Wheeler, 2008: Statistical prediction of weekly tropical cyclone activity in the Southern Hemisphere. Mon. Wea Rev., 136, 3637-3654, https://doi.org/10.1175/2008MWR2426.1.

Liebmann, B., and C. A. Smith, 1996: Description of a complete (interpolated) outgoing longwave radiation dataset. Bull. Amer. Meteor. Soc., 77, 1275-1277.

Madden, R. A., and P. R. Julian, 1971: Detection of a 40-50 day oscillation in the zonal wind in the tropical Pacific. J. Atmos. Sci., 28, 702-708, https://doi.org/10.1175/1520-0469(1971)028<0702: DOADOI $>2.0 . \mathrm{CO} ; 2$

Matthews, A. J., 2012: A multiscale framework for the origin and variability of the South Pacific Convergence Zone. Quart. J. Roy. Meteor. Soc., 138, 1165-1178, https://doi.org/10.1002/qj.1870.

Météo-France, 2008: Atlas Climatique de la Nouvelle-Calédonie. Accessed 10 December 2018, http://www.meteo.nc/en-savoir-plus/ comprendre-la-meteo/publications/atlas-climatique-de-lanouvelle-caledonie-sommaire.

Michelangeli, P.-A., R. Vautard, and B. Legras, 1995: Weather regimes: Recurrence and quasi stationarity. J. Atmos. Sci., 52, 1237-1256, https://doi.org/10.1175/1520-0469(1995)052<1237: WRRAQS $>2.0 . \mathrm{CO} ; 2$.

Mori, S., and Coauthors, 2004: Diurnal land-sea rainfall peak migration over Sumatera Island, Indonesian Maritime Continent, observed by TRMM satellite and intensive rawinsonde soundings. Mon. Wea. Rev., 132, 2021-2039, https://doi.org/ 10.1175/1520-0493(2004)132<2021:DLRPMO > 2.0.CO;2.

Moron, V., A. W. Robertson, J.-H. Qian, and M. Ghil, 2015: Weather types across the Maritime Continent: From the diurnal cycle to interannual variations. Front. Environ. Sci., 2, 65, https://doi.org/10.3389/fenvs.2014.00065.

—, R. Barbero, and A. W. Robertson, 2016: Subseasonal-tointerannual variability of rainfall over New Caledonia (SW Pacific). Climate Dyn., 46, 2449-2468, https://doi.org/10.1007/ s00382-015-2712-0.

Oh, J.-H., K.-Y. Kim, and G.-H. Lim, 2012: Impact of MJO on the diurnal cycle of rainfall over the western Maritime Continent in the austral summer. Climate Dyn., 38, 1167-1180, https:// doi.org/10.1007/s00382-011-1237-4.

Peatman, S. C., A. J. Matthews, and D. P. Stevens, 2014: Propagation of the Madden-Julian Oscillation through the Maritime Continent and scale interaction with the diurnal cycle of precipitation: MJO propagation and scale interaction with the diurnal cycle. Quart. J. Roy. Meteor. Soc., 140, 814-825, https://doi.org/10.1002/qj.2161.

Qian, J.-H., 2008: Why precipitation is mostly concentrated over islands in the Maritime Continent. J. Atmos. Sci., 65, 1428 1441, https://doi.org/10.1175/2007JAS2422.1.

— A. W. Robertson, and V. Moron, 2013: Diurnal cycle in different weather regimes and rainfall variability over Borneo associated with ENSO. J. Climate, 26, 1772-1790, https:// doi.org/10.1175/JCLI-D-12-00178.1

Rauniyar, S. P., and K. J. E. Walsh, 2011: Scale interaction of the diurnal cycle of rainfall over the Maritime Continent and
Australia: Influence of the MJO. J. Climate, 24, 325-348, https://doi.org/10.1175/2010JCLI3673.1.

Rui, H., and B. Wang, 1990: Development characteristics and dynamic structure of tropical intraseasonal convection anomalies. J. Atmos. Sci., 47, 357-379, https://doi.org/10.1175/ 1520-0469(1990)047<0357:DCADSO > 2.0.CO;2.

Saito, K., T. Keenan, G. Holland, and K. Puri, 2001: Numerical simulation of the diurnal evolution of tropical island convection over the Maritime Continent. Mon. Wea. Rev., 129, 378-400, https://doi.org/10.1175/1520-0493(2001)129<0378: NSOTDE $>2.0 . \mathrm{CO} ; 2$.

Salinger, M. J., S. McGree, F. Beucher, S. B. Power, and F. Delage, 2014: A new index for variations in the position of the South Pacific convergence zone 1910/11-2011/2012. Climate Dyn., 43, 881-892, https://doi.org/10.1007/s00382-013-2035-y.

Sobel, A. H., C. D. Burleyson, and S. E. Yuter, 2011: Rain on small tropical islands. J. Geophys. Res., 116, D08102, https://doi.org/ 10.1029/2010JD014695

Sui, C.-H., X. Li, K.-M. Lau, and D. Adamec, 1997: Multiscale airsea interactions during TOGA COARE. Mon. Wea. Rev., 125, 448-462, https://doi.org/10.1175/1520-0493(1997)125<0448: MASIDT $>2.0 . \mathrm{CO} ; 2$.

Suzuki, T., 2009: Diurnal cycle of deep convection in super clusters embedded in the Madden-Julian Oscillation. J. Geophys. Res., 114, D22102, https://doi.org/10.1029/2008JD011303.

Tian, B., D. E. Waliser, and E. J. Fetzer, 2006: Modulation of the diurnal cycle of tropical deep convective clouds by the MJO. Geophys. Res. Lett., 33, L20704, https://doi.org/10.1029/ 2006GL027752.

Vincent, C. L., and T. P. Lane, 2016: Evolution of the diurnal precipitation cycle with the passage of a Madden-Julian Oscillation event through the Maritime Continent. Mon. Wea. Rev., 144, 1983-2005, https://doi.org/10.1175/MWRD-15-0326.1.

$\longrightarrow$, and - 2017: A 10-year austral summer climatology of observed and modeled intraseasonal, mesoscale, and diurnal variations over the Maritime Continent. J. Climate, 30, 38073828, https://doi.org/10.1175/JCLI-D-16-0688.1.

Vincent, E. M., M. Lengaigne, C. E. Menkes, N. C. Jourdain, P. Marchesiello, and G. Madec, 2011: Interannual variability of the South Pacific Convergence Zone and implications for tropical cyclone genesis. Climate Dyn., 36, 1881-1896, https:// doi.org/10.1007/s00382-009-0716-3.

Wang, S., and A. H. Sobel, 2017: Factors controlling rain on small tropical islands: Diurnal cycle, large-scale wind speed, and topography. J. Atmos. Sci., 74, 3515-3532, https://doi.org/10.1175/ JAS-D-16-0344.1.

Wheeler, M. C., and H. H. Hendon, 2004: An all-season real-time multivariate MJO index: Development of an index for monitoring and prediction. Mon. Wea. Rev., 132, 1917-1932, https://doi.org/ 10.1175/1520-0493(2004)132<1917:AARMMI>2.0.CO;2.

Wilks, D. S., 2006: Statistical Methods in the Atmospheric Sciences. 2nd ed. International Geophysics Series, Vol. 100, Academic Press, $648 \mathrm{pp}$.

Yang, Y., and Y.-L. Chen, 2008: Effects of terrain heights and sizes on island-scale circulations and rainfall for the Island of Hawaii during HaRP. Mon. Wea. Rev., 136, 120-146, https:// doi.org/10.1175/2007MWR1984.1.

Yang, S., and E. A. Smith, 2006: Mechanisms for diurnal variability of global tropical rainfall observed from TRMM. J. Climate, 19, 5190-5226, https://doi.org/10.1175/JCLI3883.1.

Zhang, C., 2005: Madden-Julian Oscillation. Rev. Geophys., 43, RG2003, https://doi.org/10.1029/2004RG000158. 